\title{
Need for Early Interventions in the Prevention of Pediatric Overweight: A Review and Upcoming Directions
}

\author{
Anne M. Dattilo, ${ }^{1}$ Leann Birch, ${ }^{2}$ Nancy F. Krebs, ${ }^{3}$ Alan Lake, ${ }^{4}$ \\ Elsie M. Taveras, ${ }^{5}$ and Jose M. Saavedra ${ }^{1,4}$ \\ ${ }^{1}$ Nestlé Nutrition, 12 Vreeland Road, Florham Park, NJ 07932, USA \\ ${ }^{2}$ Department of Human Development and Family Studies, College of Health and Human Development, \\ Penn State University, S-211 Henderson South Building, University Park, PA 16802, USA \\ ${ }^{3}$ Department of Community and Behavioral Health, University of Colorado Denver, Research Complex 2, Room 5025, \\ 12700 East 19th Avenue, Box C225, Aurora, CO 80045, USA \\ ${ }^{4}$ Department of Pediatrics, Johns Hopkins University School of Medicine, 600 North Wolfe Street, Baltimore, MD 21287, USA \\ ${ }^{5}$ Obesity Prevention Program, Department of Population Medicine, Harvard Pilgrim Health Care Institute and Harvard Medical \\ School, 133 Brookline Avenue, 6th floor, Boston, MA 02215, USA \\ Correspondence should be addressed to Jose M. Saavedra, jose.saavedra@us.nestle.com
}

Received 30 December 2011; Accepted 28 February 2012

Academic Editor: Yvon Chagnon

Copyright () 2012 Anne M. Dattilo et al. This is an open access article distributed under the Creative Commons Attribution License, which permits unrestricted use, distribution, and reproduction in any medium, provided the original work is properly cited.

Childhood obesity is currently one of the most prevailing and challenging public health issues among industrialized countries and of international priority. The global prevalence of obesity poses such a serious concern that the World Health Organization (WHO) has described it as a "global epidemic." Recent literature suggests that the genesis of the problem occurs in the first years of life as feeding patterns, dietary habits, and parental feeding practices are established. Obesity prevention evidence points to specific dietary factors, such as the promotion of breastfeeding and appropriate introduction of nutritious complementary foods, but also calls for attention to parental feeding practices, awareness of appropriate responses to infant hunger and satiety cues, physical activity/inactivity behaviors, infant sleep duration, and family meals. Interventions that begin at birth, targeting multiple factors related to healthy growth, have not been adequately studied. Due to the overwhelming importance and global significance of excess weight within pediatric populations, this narrative review was undertaken to summarize factors associated with overweight and obesity among infants and toddlers, with focus on potentially modifiable risk factors beginning at birth, and to address the need for early intervention prevention.

\section{Introduction}

Based on international surveys during the past forty years, the prevalence of overweight or obesity in children has accelerated in most global regions [1]. Latest available estimates from 34 member countries within the Organization for Economic Cooperation and Development indicate that among school age children, $21 \%$ of girls and $23 \%$ of boys are overweight [2]. However, children are affected with excess weight at ages before they enter school. Worldwide, an estimated twenty-two million children $\leq 5$ years of age were overweight in 2007 [3] and at present, approximately 10$20 \%$ of infants and toddlers in the United States (US) are overweight [4], ( $\geq 85$ th body mass index (BMI) percentile for age), values similar to those reported for young children in multiple countries [5-9]. Equally concerning is the finding that nearly $10 \%$ of infants and toddlers, from birth -2 years are also obese, at or above the 95th percentile of the weight for recumbent length growth charts [4]. More than half the overweight children from one longitudinal study became overweight before age 2, and 25\% were overweight by 5 months of age [10].

Many overweight infants remain overweight into their childhood years, and childhood obesity has long been known as a strong predictor of adult obesity [11]. Recent results from a retrospective medical-chart review of 257 children 
demonstrated that an increased BMI, as early as 2 weeks of age, was associated with a significant increased risk of overweight at $6,12,36$, and 60 months [12]. Similarly, reports of overweight at 6-18 months of age being strongly predictive of weight in preschool years are becoming more often documented [13-15]. Longitudinal data from 762 infants and children (age 0-18 years) indicated that body weight as early as 2 years of age begins a positive tracking period for adult overweight; weight status from 2-6 years was the most critical growth period for prediction and realization of adult overweight [16]. An overweight child at age $2-4$ years has a 5 -fold increased risk of being overweight at age 12, compared to children not overweight during their preschool years. Although limited longitudinal data are available to categorize the proportion of overweight infants that remain overweight throughout life, infant weight status is predictive of BMI or measures of obesity during the adolescent and early adult years $[15,17-21]$. The earlier a child becomes overweight, and the longer excess weight is maintained, the greater the risk that the child's overweight will follow into adulthood.

Interventions to successfully reduce rates of overweight in very young populations are emerging areas of research, but have yet to be given adequate attention. Critical periods for establishing dietary intake patterns, eating habits, and food preferences begin in infancy, and although inconsistent, may be set as early as 2 years of age [22, 23]. As the infant progresses to table foods, the family diet exerts a strong influence on food consumption [24] consistent with a general adoption of the eating practices of the family.

Parental feeding practices, if not causative for weight status in young children, are strongly associated with body weight and healthy food choices throughout childhood [25]. Research suggests that interventions to adjust food composition or caloric intake and increase physical activity, especially after infancy, have a small impact on children's weight or measures of adiposity [26, 27] and have been inadequate in curtailing the increased prevalence of overweight affecting young children. Obesity prevention efforts that begin during the school age years offer an approach that is insufficient in addressing the epidemic. Twenty percent of U.S. preschool age children are already overweight [4], a finding that may be mirrored among other young children throughout the world $[1,9]$.

The primary objective of this narrative review is to discuss risk factors associated with early childhood overweight, with emphasis on current evidence that supports specific modifiable risk factors for obesity prevention within very young children. A review of the available, but few, interventions designed to prevent overweight and obesity within the infant age population is included. It is hoped that this review will contribute to the development of future strategies, policy, and practices consistent with the public health need for an early life obesity prevention plan.

\section{Aims and Methods of Review}

Antecedents of early childhood obesity are clearly multifactorial, and associations of varying strength have been documented for genetic, biologic, dietary, environmental, and behavioral factors. To comprehensively identify factors associated with early overweight, the referencing databases of MEDLINE, PubMed, Cochrane Central Register of Controlled Trials, and Web of Science were searched, through September 15, 2011, for studies indicating a relationship between early weight gain, overweight, or obesity and the aforementioned multifactorial categories among infants and toddlers with an average study age up to age 2 years. Potentially modifiable factors associated with weight were defined as feeding and related dietary, environmental, or behavioral practices that could be potentially modified with interventions beginning at birth. Genetic and biological factors were identified as genetic predisposition, epigenetic effects, and those within the prenatal environment. An $a$ priori exclusion was established for studies not published in the English language, without test statistics or probability levels, with less than 10 subjects completing the study, or the primary study objective was not to specifically evaluate or describe factors associated with weight or adiposity status among full term "healthy" infants and toddlers. The search strategy further applied individual and combinations of pertinent key words to the title and abstracts of referencing databases including: infant, toddler, overweight, obesity, prevention, weight, weight change, nutrition, diet, education, behavior change, and parenting practices to assess the pool of studies addressing potentially modifiable factors that may not have been secured with the more broad terms identified above.

Of the 6255 citations generated, those describing interventions or observational studies with focus on associations with weight, or reducing overweight or obesity in children younger than 2 years were selected and the introduction, discussion, and reference sections of each publication were read. The process of obtaining additional potential references was extended until no new studies were generated from these sources.

\section{Literature Search Results}

A total of 143 publications were identified as meeting selection criteria of factors significantly associated to early weight gain, overweight or obesity in children through 2 years of age. Due to the limited number of publications for some of the modifiable risk factor associations that surfaced, the search was subsequently extended to children with an average study age of $\leq 5$ years. This process yielded an additional 40 usable publications. A summary of the genetic and biologic (e.g., prenatal), and potentially modifiable (e.g., feeding and related dietary, environmental, and behavioral) factors associated with overweight within infants and young children is discussed within sections of the narrative review below.

\section{Genetic and Biological Factors Associated with Infant and Childhood Overweight}

4.1. Genetic Predisposition and Epigenetic Effects. Although strong evidence supports the role of yet non-modifiable 
genetic factors in early-onset obesity [28, 29], in and by themselves, these appear as an insufficient argument to support the increased prevalence in childhood obesity over the last three decades; genetic factors alone cannot account for the rapid secular increase. Genetic polymorphism that increases the risk for obesity $[30,31]$ may explain a small fraction of cases of childhood-onset obesity. However, in the majority children, obesity is attributed to the interaction between multiple genetic factors and an accommodating environment [32]. Continued integration of data from multiple sources of environment, genotype, and expression will help clarify obesity-related contributions from these areas [33-35]. Increasingly, it appears that epigenetic factors, heritable shifts in gene function, that do not involve changes in DNA sequence, are gaining more attention as important factors associated with childhood obesity.

Genetic predispositions related to children's weight, food intake, and dietary patterns are modulated by experience [36] and significantly influenced by the environment, including the family environment [37]. Skidmore and colleagues [38] suggested that an obesogenic postnatal environment is more important than the fetal environment for the development of obesity in female twins. Even racial and ethnic differences in the prevalence of pediatric obesity may be partly explained by differences in potentially modifiable risk factors during early infancy [39].

Not surprisingly, parental weight status is a strong predictor of childhood obesity, as parents provide genes, environment, and a diet, within a context of their particular social and behavioral settings. Children of overweight parents are at increased risk for development of obesity [40] and those, up to approximately 5 years of age, with both parents being obese have been associated with a much greater risk ( $\sim 10$ fold) for later obesity than those with one obese parent [11]. Although findings of an independent association with paternal weight and childhood weight status have been demonstrated [13], maternal weight status is consistently reported as one of the strongest correlations with their children's weight. Children of overweight mother's are nearly 3 times as likely to be overweight as children with mothers of a healthy weight [41]. Obese women tend to have large babies [42], and large for their gestational age babies are at a higher risk of becoming obese children, though not all studies have confirmed this association [15, 43]. In sum, genetic relationships are clearly associated with childhood obesity, but cannot explain all cases of childhood overweight or obesity.

4.2. Prenatal Environment. It has long been recognized that the intrauterine environment can exert effects on the developing fetus that may have long-lasting influence on health and disease into adulthood [44]. Recent epidemiological studies, from populations worldwide, have confirmed that indicators of nutritional deficit in pregnancy, such as infant low birth weight, are associated with greater risk of the infant developing adult cardiovascular disease, hypertension, or type 2 diabetes mellitus [45], all of which have independent and positive association to weight. Potential mechanisms for these developmental origins of disease are lacking, but abnormalities in the hypothalamic pituitary axis influencing metabolism, impaired fat oxidation, increased central fat distribution, and abnormal control of energy intake have been suggested $[46,47]$.

Prenatal exposure to maternal smoking during pregnancy increases risk for later obesity, and meta-analyses results confirmed that children whose mothers smoked during pregnancy were at elevated risk for overweight (pooled adjusted odds ratio (OR) 1.50, 95\% CI: 1.36, 1.65) at ages 3-33 years, compared with children whose mothers did not smoke during pregnancy [48]. Prenatal exposure to other environmental toxins that may increase the risk of childhood obesity, such as endocrine disrupting chemicals [49] are gaining attention as potential prenatal obesogenic factors.

The intrauterine environment may also be a viable source of extra macronutrients that influence birth weight. Infants that experience excess maternal gestational weight gain in utero, or that are born to mothers with diabetes, have an increased risk of being born large for their gestational age. These infants will also have a greater risk of becoming overweight, or of developing increased adiposity during their preschool [50-53], or school age years [54-56]. Although associations from observational studies described above are generally consistent with regard to infant or childhood risk of excess weight, causality has not unequivocally been established. Nevertheless, these strong associations underscore the fact that maternal obesity, or excess maternal weight gain during pregnancy, along with its attendant endocrine and other biologic disruptions, may contribute to a generational perpetuation of the problem and argues for the potential of prenatal interventions to modify the fetal environment. While meritorious, it also appears clear that if modification of maternal dietary and environmental interventions were to be attempted, some of these potential preventive measures would need to begin prior to the earliest days of gestation.

\section{Potentially Modifiable Factors Associated with Infant and Childhood Overweight}

Recent research has brought attention to specific parental feeding practices, commencing at birth, that may interact with genetic predispositions or prenatal covariates to inadvertently promote an obesogenic environment during infancy. These risk factors associated with early overweight or obesity have been identified in observational studies from both prospective and retrospective data review, with various population groups and sample sizes. Studies of mother-infant dyads from birth, with measured length and weight during infancy or toddler years, reveal important associations. However, such reports are few. Conclusions from observational studies of potentially modifiable factors associated with pediatric overweight or obesity in children up to age 5 years are presented on Table 1 .

5.1. Weight Gain during Infancy. Results from several systematic reviews are consistent in demonstrating strong evidence of a positive association between rapid infancy weight gain and later risk of obesity $[15,129,130]$. Of 
TABLE 1: Modifiable feeding and related practices associated with overweight or obesity in infants through preschool age children.

\begin{tabular}{ll}
\hline Feeding and related practices & $\begin{array}{l}\text { Direction of association to overweight or obesity in infants through preschool age } \\
\text { children }\end{array}$ \\
\hline Rate of weight gain during infancy & $\begin{array}{l}\text { Rate of weight gain, increased weight for length, BMI, or measurements of } \\
\text { adiposity during the first 2 years have been positively associated to BMI and/or } \\
\text { adiposity during the preschool years }[13,14,57,58] .\end{array}$ \\
\hline Breastfeeding & $\begin{array}{l}\text { Breastfeeding duration and/or exclusivity has been inversely associated with rate of } \\
\text { weight gain or weight measures during infancy, and with weight, adiposity or risk } \\
\text { of overweight and obesity in toddler and preschool age children [59-74]. }\end{array}$ \\
\hline Introductory age to complementary foods & $\begin{array}{l}\text { Early age of introduction to complementary foods (e.g., <4 months) has been } \\
\text { positively associated with rate of weight gain during infancy, and increased weight, } \\
\text { or measures of adiposity in infants, toddlers, and preschool age children } \\
{[69,75-81] .}\end{array}$ \\
\hline
\end{tabular}

Diet quality and quantity:

(i) Energy intake

Total energy intake has been positively associated with higher risk or prevalence of overweight in infant, toddler and preschool age children [81-85].

(ii) Intake of sweetened beverages

Intake of sugar sweetened beverages (excluding 100\% juice) has been positively related to measures of adiposity or overweight in toddler and preschool age children [84, 86-94].

(iii) Fruit and vegetable consumption Children with higher consumption of fruit and/or vegetables, or higher availability of such, consume less total energy and have been associated with a more desirable body composition or body weight during preschool years [95-99].

Parent feeding practices:

(i) Attention to "hunger and satiety cues"

Parental inattention to a child's "hunger or satiety cues" has been positively associated with overfeeding or overweight in infants [100-103].

Parental use of "controlling", "rewarding" or "restrictive" feeding practices has been associated with the child's food intake, weight gain during infancy, and overweight or obesity in preschool age children; depending on the parental feeding practice and child's age, the direction of the association has not been consistently reported $[25,104-113]$.

(ii) Use of "controlling", "rewarding" or
"restrictive" feeding practices Hours of TV or screen time viewing has been positively associated with overweight

TV/Screen viewing time or obesity in toddler and preschool age children [5, 87, 91, 114-120].

Time spent during physical activity or active play has been inversely associated with

Physical activity/active play time measures of adiposity or risk of overweight among toddler and preschool age children $[5,78,94,117,118,121]$.

Sleep duration

Sleep duration has been inversely associated with overweight, obesity, or measures of adiposity in infants, toddlers, and preschool age children [116, 119, 122-127].

Shared family meals

Frequency of a child's participation in shared family meals per week has been inversely associated with overweight, obesity, or increased risk of overweight in preschool age children $[116,128]$.

several body composition methods employed, or surrogate markers used for adiposity estimation, the association among rapid weight gain in infancy and later risk of overweight has been consistently noted from studies, worldwide [20, 5759, 131-134]. For example, weight gain during the first 2 months of life, and from 2 to 9 months, measured by dualenergy X-ray absorptiometry, was recently demonstrated in the United States to be associated with fat mass, percentage of fat mass, and fat-free mass ratio in 10-year-old children [20]. Similarly, weight gain during the first 3 months of life, and between 3-12 months, was also positively correlated with WHO BMI z-scores at age 7 in China [133], and German infants that gained weight rapidly during the first 2 years of life had greater adiposity during preschool years than those with a normal rate of growth [58]. Additionally, increases in weight-for-length or BMI during the first 18 months of life were positively associated with higher BMI, subcutaneous adiposity and obesity at 3-4 years of age $[13,14,57]$. Studies with skinfold thickness measurements [135], bioimpedance $[17,19]$, or a combination of methods $[18,136]$ reveal similar findings that early growth patterns are critical periods for development of overweight.

The more rapid and earlier an infant gains excess weight, the greater the likelihood for undesirable weight in subsequent months, and years. Although weight gain in infancy could be considered an "effect," rather than a specific obesogenic factor in early life, and the underlying mechanisms of rapid weight gain are unclear, this risk for latter obesity clearly signals the need for intervening in the early period of life. The potential to prevent early excess weight gain, through parental feeding and related practices, beginning at birth, is strong. 
5.2. Breastfeeding. Breastfeeding is recognized as the ideal feeding for infants, due to its potential for health maintenance and disease prevention [137]. Among the multiple health benefits associated with breastfeeding, a protective effect from obesity has been recognized. However, breastfeeding rates, particularly those for exclusive breastfeeding are less than ideal. Worldwide initiation rates of breastfeeding are currently near the WHO standard [138], yet globally only $34.6 \%$ of infants up to 6 months of age are exclusively breastfed, with values ranging from $43.2 \%$ within the WHO South-East Asia region, to $17.7 \%$ among babies in the European Region [139].

The U.S., Healthy People 2020 objectives for exclusive breastfeeding through 3 and 6 months of age are 46\% and $25 \%$, respectively, yet nearly $25 \%$ [60] to $42 \%$ [140] of breastfed infants in some cohorts receive formula while still in the hospital (before two days of age), decreasing the likelihood of development of a full milk supply by the mother. Moreover, recent survey data [61] indicate that $8 \%$ of mothers offered infants a combination of breastmilk and formula, from birth, during the first week of life. Among infants provided both breast milk and formula, overall breastfeeding duration was lower than those offered no formula, and when compared to infants provided 4 months of exclusive breastfeeding, the infants provided the combination of breastmilk and formula, or only formula, were at increased risk of overweight or obesity between ages 2 and 6 years [61].

Numerous studies, and at least 5 meta-analyses and systematic reviews, have examined the role of breastfeeding in relation to childhood or later obesity [141-145]. Not all conclusions are in agreement with regard to the strength of the obesity protective effect of breastfeeding; or, more correctly expressed, the increased risk of overweight with partial or full infant formula feeding in the first 4-6 months of life. However, the vast majority of studies show some degree of an inverse association between breastfeeding and risk of obesity. Conclusions vary, primarily due to inconsistency with a definition of "breastfeeding," particularly that of exclusive breastfeeding, as well as length of followup, definition of weight status, duration of breastfeeding, and confounding factors, which some analyses considered, and others did not. The statistical analyses procedures utilized to aggregate individual clinical trials may also explain differences in meta-analyses results. For example, a protective effect of breastfeeding on overweight (binary data analysis) has been reported by meta-analyses using logistic regression, whereas studies using linear regression and BMI (continuous data analysis) failed to detect meaningful significant associations [146].

Three of the five meta-analyses of observational studies found that obesity risk at school age was reduced by $15-$ $25 \%$ with "early breastfeeding" compared with formula feeding [147]. When at least three confounding factors (such as birth weight, parental weight, parental smoking, dietary factors, physical activity, or socioeconomic status) were considered, results indicated that the likelihood of obesity was $22 \%$ lower among breastfed children, compared to those not breastfed [145]. One review demonstrated a reduction in risk of obesity from $24 \%$, before statistical adjustment for confounding variables, to a $7 \%$ reduced risk of later overweight after considering paternal weight status, smoking, and socioeconomic status [141]. A separate metaanalysis determined that the risk of becoming overweight was reduced by $4 \%$ for each month of breastfeeding [144], yet the effect realized a plateau after nine months of breastfeeding. Taken together, results from the five metaanalyses identified above, published in 2004-2006, provide evidence that breastfeeding may have a relatively small, but consistent protective effect against obesity for children [60]. Newer observational studies and reviews provide additional support [59, 61-72], and as exclusive breastfeeding becomes consistently defined among studies, and tracked among study participants with future reports, results may likely be stronger for a protective breastfeeding effect on overweight prevention. Given available data, one recently released national guideline unequivocally concluded that babies who are breastfed are less likely to become overweight or obese compared to those not provided breastmilk [73]. The importance of breastfeeding, and specifically, exclusive breastfeeding, that is, avoidance of infant formula for the first 6 months of life, is a public health message that can not be over emphasized.

The mechanisms by which breastfeeding could decrease risk of overweight or obesity remain unclear. Breastfed infants tend to be leaner and gain weight more slowly throughout infancy than formula-fed infants, particularly after 3 months of age. Differences in weight gain during the first 12 months among breast fed and formula fed infants differed by $0.65 \mathrm{~kg}$ in one well matched study of 46 breastfed and 41 formula-fed infants; length and head circumference values were similar among groups [74]. Increased intake of energy, protein, or both energy and protein in formula fed infants, compared to breast fed infants, have been proposed as a factor $[148,149]$. In addition, a stronger infant self-regulation of intake has been suggested as a plausible explanation for differences among caloric intake of breastfed and formula fed infants [150].

Breastfeeding is associated with other advantages for decreasing the risk overweight development, such as parent feeding practices of a lower frequency of introducing complementary foods at ages less than 4 months, and less frequently offering high fat or high sucrose foods to infants at 1 year, compared to mothers that formula fed their infants $[140,151]$. While causality remains to be demonstrated, interactions among many obesity preventative feeding strategies may coexist with breastfeeding. Moreover, the finely regulated supply-and-demand relationship of milk production between the mother infant dyad may be disrupted with bottle feeding. Consequently, reading and interpretation of hunger and satiety cues may be significantly affected [72].

In summary, breastfeeding has at least some protective role in pediatric obesity. Although the exact subpopulation of infants most likely to benefit from obesity prevention effects has yet to be determined, numerous other health benefits of breastfeeding are indisputable. Any intervention in an infant population aimed at potentially reducing the risk of obesity would by necessity include effective encouragement, 
establishment, and continuation of exclusive breastfeeding for at least the first 6 months of life.

5.3. Introduction Age to Complementary Foods. The WHO recommendation for introduction of complementary feeding at 6 months of age has been adopted by many countries. The American Academy of Pediatrics Section on Breastfeeding, and the American Academy of Pediatrics Committee on Nutrition recommend delaying the introduction of complementary foods to at least the age of 4 months, and preferably 6 months [152]. Age-appropriate complementary foods are recommended to be introduced as indicated by the individual child's nutritional and developmental needs [153]. Although age and size often correspond with developmental readiness, these should not be used as sole considerations for deciding what and how to feed babies [154]. Provision of complementary food that is not synchronized to developmental milestones or to physiologic and immune readiness may be linked to allergies and digestive problems $[140,155]$, and early introduction of complementary foods (e.g., $<4$ months) has been positively associated with rate of weight gain during infancy, increased weight, or measures of adiposity in infants, toddlers, and preschool age children $[69,75-81]$.

Estimates for the prevalence of parents providing complementary foods prior to guidelines for developmental readiness vary. One survey of approximately 3,000 parents, completed in 2002 , documented that $26 \%$ of infants were introduced to solid foods before 4 months of age [151], and a second survey, using a similar methodology and sample size in 2008, indicated that approximately $10-15 \%$ of parents introduced infants to complementary food prior to 4 months of age [156]. Although it appears from these studies that an overall improvement in the practice of providing early complementary feeding has occurred in recent years, some racial/ethnic groups of parents may still engage in this practice at high frequencies [157]. Teaching parents to identify the appropriate developmental readiness milestones, through an anticipatory guidance approach, may be useful in delaying the inappropriate introduction of complementary foods at an early age which has been associated with early or excessive weight gain.

\subsection{Diet Quantity and Quality}

5.4.1. Energy Intake. A classic study by Stunkard and colleagues [82] was one of the first to identify that energy intake contributes significantly to body weight and measures of adiposity at 1 year of age. The contribution of energy intake (assessed via weighted food records), but not energy expenditure (measure via indirect calorimetry for sleeping and total energy expenditure), was significant in the prediction of body size in the 78 infants at one year, after considering breastfeeding status, as well as maternal BMI. Although not all studies have employed such sophisticated evaluation techniques, and some have reported neutral results for the association between BMI and energy intake within preschool age children $[158,159]$, several have reported that total energy intake is positively associated with risk or prevalence of overweight in infants, toddlers, and preschool age children [81, 83-85].

A higher dietary protein intake during infancy has also been positively associated with early weight gain during the first 2 years of life [148], although with correlations smaller than that for energy intake [85]. Randomized trials that compared growth of children fed formula of different protein concentrations showed either no association [129, $130,160]$, or a significant effect of increased protein on early infant weight gain $[148,161]$. Given that formula contains more protein, and most have a slightly higher energy density than breastmilk, these findings could explain, in part, associations among formula fed infants being at higher risk for overweight than breastfed infants. When considering the total dietary protein intake, no association with later increased BMI (at 6-7 years) was reported at 6month-old protein intake, but a higher protein intake at 12 months was independently related to increased measures of overweight in one cohort [162], and only in boys in another [163]. It appears that protein intake during the transition to the family diet is a critical point for overweight risk. By replacing carbohydrate-rich foods (fruit, vegetables) of which are low in protein and also relatively low in calories, for other energy dense foods, diet quality will naturally change. Such an alteration in macronutrient contribution and energy intake may be an effective approach to decreasing early childhood risk of obesity.

Some of the most recent comprehensive assessments of diet quality and quantity among infants and toddlers are the feeding infants and toddlers studies (FITSs). These 24hour dietary intake surveys, conducted by phone interview in 2002 and 2008 with representative, cross-sectional samples $(n>3000)$ of US parents and caregivers, in infants from birth to 48 months of age, provide detailed information on energy, nutrient intakes, and eating patterns of infants and young children $[164,165]$. Results from these studies confirm that obesity associated dietary factors are highly prevalent in the U.S. infant population.

In 2008, infants participating in the FITS survey, age birth to 5 months, consumed nearly $14 \%$ more calories $(83 \mathrm{kcal} / \mathrm{d}$ ) than estimated needs, and average energy intakes remained above estimated requirements throughout the toddler years [156]. Assuming the excess energy from the recent FITS study for the youngest infant category, and applying the first law of thermodynamics in its simplest form, after 6 weeks of 83 additional $\mathrm{kcal} / \mathrm{day}$, an estimated $0.45 \mathrm{~kg}$ weight gain would be possible, and after 6 months, an additional $1.9 \mathrm{~kg}$ of weight could be predicted. Utilizing an average weight of $7.9 \mathrm{~kg}$ for a 6-month-old infant boy, the weight differential of $1.9 \mathrm{~kg}$ corresponds to the difference between a weight for age between the 50th percentile and the 98th percentile.

High-caloric dessert foods such as cookies, cakes, candies or sweetened beverages were consumed by nearly $20 \%$ of the 6-9-month-old infants and by nearly $45 \%$ of $9-12$ month old infants. At 1 year of age, approximately 55\% of infants were consuming desserts, sweets, or sweetened beverages and by 15 months of age, two thirds of toddlers consumed this category of foods on the survey day [156] at a level of intake that tended to remain constant throughout the toddler years 
[166]. Given the energy density of these foods, and frequency of consumption, they are likely contributing to the caloric intake to a substantial degree.

5.4.2. Intake of Sweetened Beverages. Consumption of sugar sweetened beverages has been positively related to measure of adiposity or overweight in toddler and preschool age children [84, 86-94]. Specific data relating an independent association of sweetened beverage intake and weight measures are not available for infants, yet FITS data confirm that even young infants frequently consume calories from the dessert, sweets, or sweetened beverage category. Meta-analyses have established the degree to which sweetened beverage intakes in children contributes to obesity; effect sizes range from a 0.03 [167] to 0.08 unit change in BMI per $12 \mathrm{fl} \mathrm{oz}$ of soda per day [168], depending upon the length of followup, of which varied among studies. Considering the contribution of approximately 90 calories from a 6 ounce serving of a regular cola-type beverage, reducing sweetened beverage consumption among children may have a measurable impact on weight status.

5.4.3. Fruit and Vegetable Consumption. Children with high consumption or availability of fruit and/or vegetables consume less total energy and are associated with a more desirable body composition or body weight during preschool years [95-99]. However, according to the 2008 FITS data, approximately $37 \%$ of infants age $6-9$ months and $28 \%$ of $9-$ 12 -month olds did not consume a single serving of vegetables on a given day [156]. Less than $15 \%$ of infants and toddlers consumed foods from the micronutrient rich, lower-calorie, dark green vegetable category on the study survey day; instead, white potato, particularly fried potatoes, were the most frequently consumed "vegetable" of children aged 1215 months of age (18.5\%) and remained a daily dietary habit of many toddlers [166]. Of children aged 1-2 years, $33 \%$ were eating meals or snacks at a fast-food restaurant, on a given study day, which may explain the frequency of fried potato intake. The daily consumption of lower-calorie vegetables, within the infant and toddler population, could help provided a more balanced energy intake.

The American Academy of Pediatrics recommends that infants less than six months of age should not be served juice [152]. Pureed, mashed, or whole fruit is appropriate for infants once complementary feeding begins, up to one year of age, and beyond. Children aged 1-6 years should be limited to a total of four to six ounces of juice per day [153].

In summary, the studies mentioned above, all point to specific examples of modifiable practices regarding complementary food introduction which may have greater effectiveness and efficacy impact in infancy than attempting modifications in diet patterns once these are established. For example, simple messages that educate parents and caregivers about healthy feeding and dietary habits for infants and toddlers include those that encourage a wide variety of nutritious foods, especially fruits and vegetables, in forms and times that are developmentally appropriate for the child $[169,170]$, and with frequency and persistence of offerings to generate acceptance. Planning toddler's snacks, of which contribute about $25 \%$ of a toddler's daily energy intakes [171] to complement meals by including fruits, vegetables and whole grains, rather than sugar-sweetened drinks and desert-type foods, as well as limiting exposure to fried fast food restaurant foods, all provide additional practical examples of modifiable healthy food practices that parents can foster [166].

5.5. Parent Feeding Practices. If provided the opportunity, infants and young toddlers will exert a relatively robust innate ability to regulate energy intake [172-175]. However, innate self-regulation of caloric intake can be easily overridden by environmental factors, including wellmeaning, yet misguided parent feeding practices. Although a complex relationship has been proposed, correlational evidence is increasingly being documented linking parent feeding practices to infant or childhood weight status [104, 105, 176-178], even when considering several confounding variables [95]. However, as described below, depending on the particular feeding practice, and age of the child, the directionality of the relationship varies.

5.5.1. Attention to "Hunger and Satiety Cues". Parental inattention to an infant's hunger and satiety cues has been associated with weight gain at 4-5 months [100], predictive of weight gain at 6-12 months [101], and related to infant and toddler weight-for-length $\mathrm{z}$ scores [102]. Inadequate feeding practices associated with bottle feeding of infant formula, where hunger and satiety cues may require more attention to be recognized compared to breastfeeding, or the use of bottle feeding as a method for soothing infants, may also contribute to greater than expected energy intake in early life. Lack of responsive parent feeding practices, such as inattention to a child's hunger or satiety cues, has been positively associated with infant overfeeding or overweight [100-103].

In contrast, "responsive feeding," where the parents or caregivers recognize and respond to infant cues for hunger and satiety helps foster trust and appears to reduce potential overfeeding [153]. Feeding infants on cue, rather than on a schedule, may help prevent childhood obesity [72], for when infants are "cue fed," they are in control of frequency and amount of feedings [153]. As a consequence, very early attention and appropriate responsiveness by parents to hunger and satiety cues may have long reaching effects on feeding practices of children.

It is unlikely that parent feeding practices of low attention to infant cues for hunger and satiety are transient, or that children do not adapt to such by learning to overeat. At 2 years of age, children participating in laboratory tasks designed to assess their self-regulation skills that ranked lower on inhibitory control and higher on reward sensitivity skills were more likely to be overweight at 5 years of age than their counterparts [179]. In addition, children (3-5 years) in higher weight categories had lower satiety response and higher response to food cues, even after controlling for parental education and BMI [180]. Parental education about reading appropriate hunger cues presented by the infant and 
responding appropriately with timing, amount, and pacing of early feeding of nutritious food, as well as a parental acceptance of alternative soothing options, rather than immediate feeding, may be helpful to prevent overfeeding.

5.5.2. Use of "Controlling," "Rewarding," or "Restrictive" Feeding Practices. Excessive "maternal control during feeding" at the weaning period [104] or childhood years [181], and parental use of food as a solace or reward for their children [182], have been rather consistently implicated as factors associated with unhealthy eating or weight gain in children. Offering food as a reward or punishment places undue importance on food and may have negative effects leading to obesity or poor eating behavior. When parental control is applied in a general atmosphere of involvement and parental warmth (e.g., authoritative parenting style from the child development literature [183]), it has led to positive food choices by young children [184], healthy eating [184-186], and obesity prevention [176, 187]. Children are responsible for participating in choices about food selection (within the healthy food options provided by the parent) and should be allowed to take responsibility for determining how much is consumed at each eating occasion [155]. Using this approach, along with providing small portions of new foods and praising the child for eating healthy foods has been positively associated with consumption of nutritious foods by preschool age children [188].

In contrast, parental restriction of children's eating or restricting their access to food [25, 106-110, 189-193], particularly if fueled by parental concern about overeating [194] or child's weight [111], has been frequently associated with childhood weight gain, particularly in older children. However, parental restriction did not predict change in a sample of preschool age children's eating behavior [112], and a favorable influence of parental food restriction on the intake of energy-dense foods and snacks has been reported among toddlers [113]. Research to address the directionality of relationships among some parent feeding behaviors with infants and toddlers is needed.

Although associations between parental feeding practices and subsequent early childhood risk of overweight are well documented, due the nature of the observational research, a causal relation cannot be concluded. It is difficult to discern if certain child factors evoke parenting feeding practices, or whether parent feeding practices influence these child factors. Moreover, as reviewed by Ventura and Birch [195], and Anzman and colleagues [196], the majority of research in the arena of parent feeding practices and childhood weight is cross-sectional, or performed in a feeding-laboratory setting. Few studies have systematically examined whether an intervention program designed to educate parents on the potential role their infant or child feeding practices could play on the weight status of their young children are available.

Given the above findings, educational interventions on feeding practices with high responsiveness to hunger and satiety cues, and allowing for early self-regulation of food intake by the infant, are needed to curb the potential adverse effects that parent feeding practices can have on children's innate ability to regulate energy intake [172].
Interventions for obesity prevention that do not address parenting approaches to feeding are unlikely to be successful [197].

\subsection{TV/Screen Viewing Time and Physical Activity/Active} Play. The American Academy of Pediatrics consensus Statement on Prevention and Treatment of Childhood Obesity [198] recommends that children 2 years old and younger should not be exposed to television, and children over age 2 should limit daily media exposure to only 1-2 hours of quality programming for TV viewing and screen use. In contrast to these recommendations, survey data show that by 3 months of age, approximately $40 \%$ of infants regularly watch videos, DVD's, or television and $90 \%$ of children under age 2 watch television daily [199]. Moreover, these early screen-viewing patterns appear to persist into childhood [200].

There is solid evidence that increased TV viewing and screen time has been associated with overweight, obesity, or adiposity in toddler and pre-school children within multiple cohorts and studies $[5,87,91,114-120]$. The influence of TV and screen time watching on body weight is likely related to the sedentary nature of viewing and displacement of activity, yet also to the quality and quantity of foods consumed while watching TV, particularly during mealtimes. Among toddler age children, TV viewing was associated with higher intakes of calories, sugar-sweetened beverages, fast food, and less fruit and vegetable consumption [201]. TV watching during mealtime was also a strong predictor of toddler's "unhealthy" food consumption, primarily mediated through their mother's TV viewing of which affected her own food intake, in turn, influencing the toddler's food consumption pattern [202]. TV viewing has been associated with foods consumed by school age children [203], including more pizza, salty snacks, fast foods, and soda, and fewer vegetables or whole grains while watching TV during mealtimes, compared to meals consumed without TV [204, 205].

In addition to limits for TV, daily physical activity can prevent a rapid gain in weight which leads to obesity early in life [153]. Several studies have documented an inverse association with time spent during active play/physical activity and measures of adiposity or risk of overweight among toddler and preschool age children [5, 78, 94, 117, $118,121]$. Although some experts recommend that infants should have supervised "tummy time" every day when they are awake and that confining infant equipment such as swings, infant seats (e.g., bouncers), if used, should only be allowed for short periods of time [206], data to evaluate the prevalence of these behaviors at home, or in infant care settings, and their association to overweight, obesity, or rapid weight gain in infancy are not available.

Parents may need education and encouragement to provide a least restrictive environment to foster active play time for their young infants and opportunities for gross motor activity [207-210]. Early infancy and childhood interventions geared to risk reduction of overweight and obesity should include education on risks associated to screen time, and on physically active alternatives to screen time to encourage motor development in young children. 
5.7. Sleep Duration. Since an early report in 1992, suggesting that short sleep duration is associated with childhood obesity [211], multiple observational studies have documented an inverse relationship between sleep duration and measures of adiposity, overweight, or obesity with infant, toddler, and the preschool age children [116, 119, 122-127]. Recently, shorter sleep duration during infancy $(<12$ hours/day) has been associated with higher BMI z score, skinfold measures, and increased odds of overweight in 3-year-old children [123].

Parenting behaviors surrounding sleep duration in infancy may influence sleeping patterns for life. Infants of whom do not sleep for at least 6 hours nightly by age 5 months have a greater risk of short nocturnal sleep duration later in childhood $[212,213]$ and one longitudinal study of sleep in children reported that sleep duration for age, compared with "norms," remained constant for nearly $90 \%$ of children age 1-10 years [214]. Thus, it appears, albeit from limited data, that sleep duration during infancy sets the stage for sleeping patterns throughout childhood.

Mechanisms to help explain the relationship between sleep and overweight are based on both physiological and behavioral findings. Biochemical markers are limited for infants and young children; however, sleep restriction in adults has been associated with increases in the appetite stimulating peptide, ghrelin, and a reduction in the anorexigenic hormone, leptin [215-217]. Although one study with infants identified that lower cord blood ghrelin was associated with slower weight gain from 0-to-3-month-old infants [218], confirmation from larger studies of infants, addressing the influence of confounding variables, is not currently available.

Parental feeding practices, related to infant sleeping, may have a strong impact on early and rapid weight gain. The possibility that food, especially bottle feeding and early introduction of complementary food [157] used by parents as an approach to calm an overtired-fussy infant [100, 219221] or as a "sleep aid for infants" may be part of the explanation for these associations. Recent interventions that promote the use of alternative approaches to feeding for soothing a fussy infant or increasing nocturnal sleep duration have reported encouraging results [222, 223]. Given findings of observational studies indicating sleep duration, particularly that nocturnal sleep duration during infancy and early childhood is associated with pediatric obesity, addressing this variable as part of a multicomponent pediatric prevention program for healthy weight has been recommended [224].

5.8. Shared Family Meals. Families that regularly eat meals together are likely to positively impact the nutritional health and weight in the children [225]. Meta-analysis of 17 studies of children (age 2.8 years and older) that examined children's weight status, food consumption, and eating patterns identified a $12 \%$ reduction in odds of pediatric overweight (e.g., $>85$ th percentile) with a family meal frequency of 3 or more meals together per week [128]. The majority of studies included children of adolescent age; however, when age was tested as a potential moderator, it was found to be nonsignificant. Similarly, cross-sectional analysis of a nationally representative sample of $\sim 8550$ 4-year-old children reported that children of whom engaged in eating family meals at least 5 or more evenings per week were at a $16 \%$ decreased risk of obesity ( $>95$ th percentile), compared to those consuming fewer family meals together [116]. Although there is little evidence specifically linking family meal participation of older infants and toddlers to obesity, high rates of infants eating outside the home, in fast food store restaurants, have been reported [166]. Family meal time may be a contributor to pediatric overweight for preschool age and older children, and fostering this practice in younger children may have broad benefits, and is unlikely to cause harm.

In summary of the aforementioned potentially modifiable parent feeding and related practices that correlate with pediatric obesity, some within the very youngest infants, a fully causal relationship remains to be established. Prospective and well-controlled interventional studies, offering a practical and generalizable way to address the feeding and parent related practices associated with childhood obesity are urgently needed to address the obesity epidemic.

\section{Evidence for Obesity Prevention Strategies with Infants}

A great deal is known of the multiple factors associated to obesity, including those associating factors in infancy to obesity, but the documentation of causality remains unclear. The time for additional observational studies is passing us by, and research of interventions that may be efficacious to change the course of the epidemic is overdue. However, to date, few studies have examined the efficacy of interventions for obesity prevention that target infant populations [226]. Only three recent published studies with results of the efficacy of assessing specific interventions for prevention of overweight in early infancy could be identified. As described below, results are mixed.

A randomized, controlled, pilot trial in the U.S., with 110 mother-infant dyads recently reported positive results for their two-component intervention in preventing overweight during infancy among primarily breastfed infants [223]. Interventions were provided by home-nurse visits, consisting of educational content addressing alternative strategies to feeding for soothing a fussy baby, complementary feeding information, a feeding demonstration, and guidance on recognizing hunger and fullness cues. In this study, infants who were provided a "soothe/sleep education intervention" at 23 weeks of life, and "introduction to solid food education" between 4-6 months of life, realized a significantly lower weight-for-length percentile at one year of age. Despite study limitations of a relatively small sample size, results indicated that the intervention was effective in helping infants achieve healthy growth, likely through the influence of increases in nocturnal sleep duration, delayed introduction of solid foods, and increases in consumption of vegetable foods.

A second recently published pilot study included 80 infants enrolled during the first week of life, and their postpartum mothers, to assess impact of an education program on infant feeding, sleep duration, TV viewing and mothers' responsiveness to their infants satiety cues [222]. In addition, 
the intervention aimed to influence the mother's postpartum diet, activity, TV, and sleep behaviors. After 6 months of brief pediatrician messages, motivational interviewing/coaching by health educators, and group parenting workshops, significantly fewer intervention infants had been introduced to solid foods, compared to the usual care-control group. Intervention infants viewed less TV, had larger increases in nocturnal sleep duration, and required less settling time than infants provided usual care. No significant differences in infant weight status were detected; however, trends indicated a lower change in weight-for-length $\mathrm{z}$ scores and fewer infants were found in the highest quartiles of weight-forlength among intervention, compared to control, infants. Although this nonrandomized, pediatrician-based, intervention program was not directly effective in influencing maternal postpartum behaviors regarding their own weight, the multicomponent intervention tended to improve infant weight related behaviors employed by the mothers.

A third double-blind, randomized educational intervention study enrolled 3-10-week-old, exclusively formulafed infants. The educational intervention consisted of one session that focused on recognizing signs of infant satiety and limiting formula volume to no more than $6 \mathrm{oz}$ per bottle. No difference among intervention $(n=44)$ and control infants ( $n=57$ ) with regard to weight gain, formula intake, or parental behavior was realized when assessed at 4 months. The study was limited by a small sample size and high loss to followup [100].

\section{Upcoming Directions}

Although a limited number of potentially modifiable factors associated with early childhood overweight have been identified within the published literature, interventions to examine the impact of these factors on prevention of overweight have not been adequately studied. While comprehensive approaches dealing with all aspects of the "global epidemic," at all ages are important and necessary, including pre gestational interventions in fertile women, the first two years of life provide a potential window of opportunity like no other, to establish feeding, dietary, and behavioral patterns that remain with an individual throughout life.

Randomized controlled trials for obesity prevention in infants that address multiple intervention components are on the horizon, and study protocols have been published by at least three groups in Australia [7, 227, 228], one in London [229], one in Italy [230], and another in the USA [231]. To date, one study in Australia [7], and another in New Zealand [8] targets infants from birth; participant acceptance of the former intervention is reported as positive [232], and results of impact on obesity prevention are pending.

Another exploratory, randomized controlled trial is currently underway in the United Kingdom with infants under 18 months, and aims to prevent further obesity in high risk infants (those with weight $>95$ th percentile, or a preschool age sibling with obesity, or a mother with obesity). Preliminary results, published as qualitative pilot data, suggest that this multicomponent intervention may serve as a potentially effective approach for obesity prevention within the high risk weaning age child [233].

Causal relationships among potentially modifiable factors and overweight during infancy and young childhood have yet to be firmly established. The potential implementation of a successful intervention strategy to help identify which intervention components are most effective would have meaningful effects on public health and public policy.

\section{Conclusion}

The prevalence of obesity in infants and toddlers, and its long-term weight status consequences, points to the necessity, as well as the potential for interventions which focus on this age group. Clearly, there are genetic, biologic, and prenatal factors that will need to be addressed, some of which may not be modifiable, others which may come about more slowly. Obesity prevention strategies encouraging a healthy rate of weight gain in the early months of life, breastfeeding exclusivity, timely introduction of nutrient dense, energy appropriate foods, adequate infant sleep, and attention to activity/screen viewing, provided to infants and young children with responsive parental feeding practices in a family meal setting are suggested. Few studies have proposed a comprehensive nutritionally and developmentally appropriate intervention, starting at birth, designed to promote healthy dietary intake, an appropriate early growth trajectory, and a long-term weight status that is consistent with public health recommendations. Given the apparent ontogenetic progression, the metabolic programming plasticity, and the behavioral modeling pliability of infancy, this may be the most critical and potentially efficacious window of opportunity available for true "prevention" of obesity in the general population. Overweight and obesity are already identifiable in infancy. Interventions within the very early months and years of life are critical times for addressing potentially modifiable factors for overweight and obesity prevention.

\section{References}

[1] Y. Wang and T. Lobstein, "Worldwide trends in childhood overweight and obesity," International Journal of Pediatric Obesity, vol. 1, no. 1, pp. 11-25, 2006.

[2] International Obesity Task Force prevalence Data, "Global childhood overweight," http://www.oecd.org/, 2011.

[3] J. Lanigan, S. Barber, and A. Singhal, "Session 3 (Joint with the British Dietetic Association): management of obesity prevention of obesity in preschool children," Proceedings of the Nutrition Society, vol. 69, no. 2, pp. 204-210, 2010.

[4] C. L. Ogden, M. D. Carroll, L. R. Curtin, M. M. Lamb, and K. M. Flegal, "Prevalence of high body mass index in US children and adolescents, 2007-2008," Journal of the American Medical Association, vol. 303, no. 3, pp. 242-249, 2010.

[5] J. Jiang, U. Rosenqvist, H. Wang, T. Greiner, Y. Ma, and A. M. Toschke, "Risk factors for overweight in 2- to 6-year-old children in Beijing, China," International Journal of Pediatric Obesity, vol. 1, no. 2, pp. 103-108, 2006.

[6] Y. Manios, G. Moschonis, E. Grammatikaki, A. Anastasiadou, and T. Liarigkovinos, "Determinants of childhood obesity and association with maternal perceptions of their children's 
weight status: the "GENESIS" study," Journal of the American Dietetic Association, vol. 110, no. 10, pp. 1527-1531, 2010.

[7] L. M. Wen, L. A. Baur, C. Rissel, K. Wardle, G. Alperstein, and J. M. Simpson, "Early intervention of multiple home visits to prevent childhood obesity in a disadvantaged population: a home-based randomised controlled trial (Healthy Beginnings Trial)," BMC Public Health, vol. 7, article no. 76, 2007.

[8] L. M. Askie, L. A. Baur, K. Campbell et al., "The early prevention of obesity in children (EPOCH) collaborationan individual patient data prospective meta-analysis," $B M C$ Public Health, vol. 10, article no. 728, 2010.

[9] A. Cattaneo, L. Monasta, E. Stamatakis et al., "Overweight and obesity in infants and pre-school children in the European Union: a review of existing data," Obesity Reviews, vol. 11, no. 5, pp. 389-398, 2010.

[10] J. W. Harrington, V. Q. Nguyen, J. F. Paulson, R. Garland, L. Pasquinelli, and D. Lewis, "Identifying the "tipping point" age for overweight pediatric patients," Clinical Pediatrics, vol. 49, no. 7, pp. 638-643, 2010.

[11] R. C. Whitaker, J. A. Wright, M. S. Pepe, K. D. Seidel, and W. H. Dietz, "Predicting obesity in young adulthood from childhood and parental obesity," New England Journal of Medicine, vol. 337, no. 13, pp. 869-873, 1997.

[12] J. D. Winter, P. Langenberg, and S. D. Krugman, "Newborn adiposity by body mass index predicts childhood overweight," Clinical Pediatrics, vol. 49, no. 9, pp. 866-870, 2010.

[13] I. Öhlund, O. Hernell, A. Hörnell, H. Stenlund, and T. Lind, "BMI at 4 years of age is associated with previous and current protein intake and with paternal BMI," European Journal of Clinical Nutrition, vol. 64, no. 2, pp. 138-145, 2010.

[14] E. M. Taveras, S. L. Rifas-Shiman, M. B. Belfort, K. P. Kleinman, E. Oken, and M. W. Gillman, "Weight status in the first 6 months of life and obesity at 3 years of age," Pediatrics, vol. 123, no. 4, pp. 1177-1183, 2009.

[15] N. Stettler and V. Iotova, "Early growth patterns and longterm obesity risk," Current Opinion in Clinical Nutrition and Metabolic Care, vol. 13, no. 3, pp. 294-299, 2010.

[16] M. L. A. De Kroon, C. M. Renders, J. P. Van Wouwe, S. Van Buuren, and R. A. Hirasing, "The Terneuzen Birth Cohort: BMI changes between 2 and 6 years correlate strongest with adult overweight," PLoS One, vol. 5, no. 2, Article ID e9155, 2010.

[17] J. Botton, B. Heude, J. Maccario et al., "Postnatal weight and height growth velocities at different ages between birth and $5 \mathrm{y}$ and body composition in adolescent boys and girls," American Journal of Clinical Nutrition, vol. 87, no. 6, pp. 1760-1768, 2008.

[18] S. Chomtho, J. C. K. Wells, J. E. Williams, P. S. W. Davies, A. Lucas, and M. S. Fewtrell, "Infant growth and later body composition: evidence from the 4-component model," American Journal of Clinical Nutrition, vol. 87, no. 6, pp. 1776-1784, 2008.

[19] M. Eriksson, P. Tynelius, and F. Rasmussen, "Associations of birthweight and infant growth with body composition at age 15-the COMPASS study," Paediatric and Perinatal Epidemiology, vol. 22, no. 4, pp. 379-388, 2008.

[20] K. K. Ong, P. Emmett, K. Northstone et al., "Infancy weight gain predicts childhood body fat and age at menarche in girls," Journal of Clinical Endocrinology and Metabolism, vol. 94, no. 5, pp. 1527-1532, 2009.

[21] N. Stettler, "Nature and strength of epidemiological evidence for origins of childhood and adulthood obesity in the first year of life," International Journal of Obesity, vol. 31, no. 7, pp. 1035-1043, 2007.
[22] J. D. Skinner, B. R. Carruth, W. Bounds, and P. J. Ziegler, "Children's food preferences: a longitudinal analysis," Journal of the American Dietetic Association, vol. 102, no. 11, pp. 1638-1647, 2002.

[23] E. Cashdan, "A sensitive period for learning about food," Human Nature, vol. 5, no. 3, pp. 279-291, 1994.

[24] J. T. Dwyer, C. W. Suitor, and K. Hendricks, "FITS: new insights and lessons learned," Journal of the American Dietetic Association, vol. 104, no. 1, pp. S5-S7, 2004.

[25] H. R. Clark, E. Goyder, P. Bissell, L. Blank, and J. Peters, "How do parents' child-feeding behaviours influence child weight? Implications for childhood obesity policy," Journal of Public Health, vol. 29, no. 2, pp. 132-141, 2007.

[26] C. D. Summerbell, E. Waters, L. D. Edmunds, S. Kelly, T. Brown, and K. J. Campbell, "Interventions for preventing obesity in children," Cochrane Database of Systematic Reviews, no. 3, Article ID CD001871, 2005.

[27] H. O. Luttikhuis, L. Baur, H. Jansen et al., "Interventions for treating obesity in children," Cochrane Database of Systematic Reviews, no. 1, Article ID CD001872, 2009.

[28] A. J. Stunkard, J. R. Harris, N. L. Pedersen, and G. E. McClearn, "The body-mass index of twins who have been reared apart," New England Journal of Medicine, vol. 322, no. 21, pp. 1483-1487, 1990.

[29] A. Scherag, C. Dina, A. Hinney et al., "Two new loci for bodyweight regulation identified in a joint analysis of genomewide association studies for early-onset extreme obesity in French and German study groups," PLoS Genetics, vol. 6, no. 4, 2010.

[30] C. G. Bell, A. J. Walley, and P. Froguel, "The genetics of human obesity," Nature Reviews Genetics, vol. 6, no. 3, pp. 221-234, 2005.

[31] W. K. Chung and R. L. Leibel, "Molecular physiology of syndromic obesities in humans," Trends in Endocrinology and Metabolism, vol. 16, no. 6, pp. 267-272, 2005.

[32] D. M. Mutch and K. Clement, "Genetics of human obesity," Best Practice \& Research: Clinical Endocrinology \& Metabolism, vol. 20, pp. 647-664, 2006.

[33] L. Trasande, C. Cronk, M. Durkin et al., "Environment and obesity in the national children's study," Environmental Health Perspectives, vol. 117, no. 2, pp. 159-166, 2009.

[34] H. Zheng, N. R. Lenard, A. C. Shin, and H. R. Berthoud, "Appetite control and energy balance regulation in the modern world: reward-driven brain overrides repletion signals," International Journal of Obesity, vol. 33, no. 2, pp. S8-S13, 2009.

[35] H. R. Berthoud, N. R. Lenard, and A. C. Shin, "Food reward, hyperphagia, and obesity," American Journal of Physiology, vol. 300, no. 6, pp. 1266-1277, 2011.

[36] S. Scaglioni, M. Salvioni, and C. Galimberti, "Influence of parental attitudes in the development of children eating behaviour," British Journal of Nutrition, vol. 29, no. 1, pp. S22-S25, 2008.

[37] J. Wardle and L. Cooke, "Genetic and environmental determinants of children's food preferences," British Journal of Nutrition, vol. 29, no. 1, pp. S15-S21, 2008.

[38] P. M. L. Skidmore, A. Cassidy, R. Swaminathan et al., "An obesogenic postnatal environment is more important than the fetal environment for the development of adult adiposity: a study of female twins," American Journal of Clinical Nutrition, vol. 90, no. 2, pp. 401-406, 2009.

[39] E. M. Taveras, M. W. Gillman, K. Kleinman, J. W. RichEdwards, and S. L. Rifas-Shiman, "Racial/ethnic differences 
in early-life risk factors for childhood obesity," Pediatrics, vol. 125, no. 4, pp. 686-695, 2010.

[40] R. A. Price, A. J. Stunkard, R. Ness et al., "Childhood onset (age < 10) obesity has high familial risk," International Journal of Obesity, vol. 14, no. 2, pp. 185-195, 1990.

[41] S. Danielzik, K. Langnäse, M. Mast, C. Spethmann, and M. J. Müller, "Impact of parental BMI on the manifestation of overweight 5-7 year old children," European Journal of Nutrition, vol. 41, no. 3, pp. 132-138, 2002.

[42] H. M. Salihu, A. K. Mbah, A. P. Alio, J. L. Kornosky, K. Bruder, and V. Belogolovkin, "Success of programming fetal growth phenotypes among obese women," Obstetrics and Gynecology, vol. 114, no. 2, pp. 333-339, 2009.

[43] A. J. Stunkard, R. I. Berkowitz, V. A. Stallings, and J. R. Cater, "Weights of parents and infants: is there a relationship?" International Journal of Obesity and Related Metabolic Disorders, vol. 23, pp. 159-162, 1999.

[44] D. J. P. Barker, C. Osmond, J. Golding, D. Kuh, and M. E. J. Wadsworth, "Growth in utero, blood pressure in childhood and adult life, and mortality from cardiovascular disease," British Medical Journal, vol. 298, no. 6673, pp. 564-567, 1989.

[45] D. J. Hoffman, "Early nutrition and adult health: perspectives for international and community nutrition programs and policies," Nutrition Research and Practice, vol. 4, no. 6, pp. 449-454, 2010.

[46] S. L. Henry, B. Barzel, R. J. Wood-Bradley, S. L. Burke, G. A. Head, and J. A. Armitage, "The developmental origins of obesity-related hypertension," Clinical and Experimental Pharmacology and Physiology. In press.

[47] D. Szostak-Wegierek and K. Szamotulska, "Fetal development and risk of cardiovascular diseases and diabetes type 2 in adult life," Medycyna Wieku Rozwojowego, vol. 15, pp. 203-215, 2011.

[48] E. Oken, E. B. Levitan, and M. W. Gillman, "Maternal smoking during pregnancy and child overweight: systematic review and meta-analysis," International Journal of Obesity, vol. 32, no. 2, pp. 201-210, 2008.

[49] R. R. Newbold, E. Padilla-Banks, R. J. Snyder, T. M. Phillips, and W. N. Jefferson, "Developmental exposure to endocrine disruptors and the obesity epidemic," Reproductive Toxicology, vol. 23, no. 3, pp. 290-296, 2007.

[50] M. W. Gillman, S. L. Rifas-Shiman, K. Kleinman, E. Oken, J. W. Rich-Edwards, and E. M. Taveras, "Developmental origins of childhood overweight: potential public health impact," Obesity, vol. 16, no. 7, pp. 1651-1656, 2008.

[51] E. Oken, E. M. Taveras, K. P. Kleinman, J. W. Rich-Edwards, and M. W. Gillman, "Gestational weight gain and child adiposity at age 3 years," American Journal of Obstetrics and Gynecology, vol. 196, no. 4, pp. 322-328.e1, 2007.

[52] K. L. Lewis, B. C. Castrucci, G. Gossman et al., "Overweight among low-income Texas preschoolers aged 2 to 4 years," Journal of Nutrition Education and Behavior, vol. 42, no. 3, pp. 178-184, 2010.

[53] C. S. Wright, S. L. Rifas-Shiman, J. W. Rich-Edwards, E. M. Taveras, M. W. Gillman, and E. Oken, "Intrauterine exposure to gestational diabetes, child adiposity, and blood pressure," American Journal of Hypertension, vol. 22, no. 2, pp. 215-220, 2009.

[54] E. Oken, S. L. Rifas-Shiman, A. E. Field, A. L. Frazier, and M. W. Gillman, "Maternal gestational weight gain and offspring weight in adolescence," Obstetrics and Gynecology, vol. 112, no. 5, pp. 999-1006, 2008.
[55] B. H. Wrotniak, J. Shults, S. Butts, and N. Stettler, "Gestational weight gain and risk of overweight in the offspring at age $7 \mathrm{y}$ in a multicenter, multiethnic cohort study," American Journal of Clinical Nutrition, vol. 87, no. 6, pp. 1818-1824, 2008.

[56] M. M. Lamb, D. Dabelea, X. Yin et al., "Early-life predictors of higher body mass index in healthy children," Annals of Nutrition and Metabolism, vol. 56, no. 1, pp. 16-22, 2010.

[57] L. Dubois and M. Girard, "Early determinants of overweight at 4.5 years in a population-based longitudinal study," International Journal of Obesity, vol. 30, no. 4, pp. 610-617, 2006.

[58] N. Karaolis-Danckert, A. L. B. Günther, A. Kroke, C. Hornberg, and A. E. Buyken, "How early dietary factors modify the effect of rapid weight gain in infancy on subsequent bodycomposition development in term children whose birth weight was appropriate for gestational age," American Journal of Clinical Nutrition, vol. 86, no. 6, pp. 1700-1708, 2007.

[59] M. W. Gillman, "The first months of life: a critical period for development of obesity," American Journal of Clinical Nutrition, vol. 87, no. 6, pp. 1587-1589, 2008.

[60] Centers for Disease Control and Prevention, "Breastfeeding among U.S. children born 1999-2007," CDC National Immunization Survey, 2010, http://www.cdc.gov/ breastfeeding/data/NIS_data/index.htm.

[61] A. V. Holmes, P. Auinger, and C. R. Howard, "Combination feeding of breast milk and formula: evidence for shorter breast-feeding duration from the national health and nutrition examination Survey," Journal of Pediatrics, vol. 159, no. 2, pp. 186-191, 2011.

[62] B. Durmuş, L. Van Rossem, L. Duijts et al., "Breastfeeding and growth in children until the age of 3 years: the Generation R Study," British Journal of Nutrition, vol. 105, no. 11, pp. 1704-1711, 2011.

[63] I. Gunnarsdottir, L. Schack-Nielsen, K. F. Michaelsen, T. I. A. Sørensen, and I. Thorsdottir, "Infant weight gain, duration of exclusive breast-feeding and childhood BMI-two similar follow-up cohorts," Public Health Nutrition, vol. 13, no. 2, pp. 201-207, 2010.

[64] J. Baird, J. Poole, S. Robinson et al., "Milk feeding and dietary patterns predict weight and fat gains in infancy," Paediatric and Perinatal Epidemiology, vol. 22, no. 6, pp. 575-586, 2008.

[65] L. J. Griffiths, L. Smeeth, S. Sherburne Hawkins, T. J. Cole, and C. Dezateux, "Effects of infant feeding practice on weight gain from birth to 3 years," Archives of Disease in Childhood, vol. 94, no. 8, pp. 577-582, 2009.

[66] S. M. Robinson, L. D. Marriott, S. R. Crozier et al., "Variations in infant feeding practice are associated with body composition in childhood: a prospective cohort study," Journal of Clinical Endocrinology and Metabolism, vol. 94, no. 8, pp. 2799-2805, 2009.

[67] D. C. James and R. Lessen, "Position of the American Dietetic Association: promoting and supporting breastfeeding," Journal of the American Dietetic Association, vol. 109, no. 11, pp. 1926-1942, 2009.

[68] J. S. Gubbels, C. Thijs, A. Stafleu, S. Van Buuren, and S. P. J. Kremers, "Association of breast-feeding and feeding on demand with child weight status up to 4 years," International Journal of Pediatric Obesity, vol. 6, no. 2, pp. e515-e522, 2011.

[69] S. S. Hawkins, T. J. Cole, and C. Law, "An ecological systems approach to examining risk factors for early childhood overweight: findings from the UK Millennium Cohort Study," 
Journal of Epidemiology and Community Health, vol. 63, no. 2, pp. 147-155, 2009.

[70] R. Li, S. B. Fein, and L. M. Grummer-Strawn, "Association of breastfeeding intensity and bottle-emptying behaviors at early infancy with infants' risk for excess weight at late infancy," Pediatrics, vol. 122, no. 2, pp. S77-S84, 2008.

[71] B. Rebhan, M. Kohlhuber, U. Schwegler, H. Fromme, M. Abou-Dakn, and B. V. Koletzko, "Breastfeeding duration and exclusivity associated with infants' health and growth: data from a prospective cohort study in Bavaria, Germany," Acta Paediatrica, International Journal of Paediatrics, vol. 98, no. 6, pp. 974-980, 2009.

[72] E. M. Taveras, S. L. Rifas-Shiman, K. S. Scanlon, L. M. Grummer-Strawn, B. Sherry, and M. W. Gillman, "To what extent is the protective effect of breastfeeding on future overweight explained by decreased maternal feeding restriction?" Pediatrics, vol. 118, no. 6, pp. 2341-2348, 2006.

[73] US Department of Health and Human Services, The Surgeon General's Call to Action to Support Breastfeeding, US Department of Health and Human Services, Office of the Surgeon General, Washington, DC, USA, 2011.

[74] K. G. Dewey, M. J. Heinig, L. A. Nommsen, J. M. Peerson, and B. Lonnerdal, "Growth of breast-fed and formula-fed infants from 0 to 18 months: the DARLING study," Pediatrics, vol. 89, no. 6, pp. 1035-1041, 1992.

[75] J. L. Baker, K. F. Michaelsen, K. M. Rasmussen, and T. I. A. Sørensen, "Maternal prepregnant body mass index, duration of breastfeeding, and timing of complementary food introduction are associated with infant weight gain," American Journal of Clinical Nutrition, vol. 80, no. 6, pp. 1579-1588, 2004.

[76] S. Y. Huh, S. L. Rifas-Shiman, E. M. Taveras, E. Oken, and M. W. Gillman, "Timing of solid food introduction and risk of obesity in preschool-aged children," Pediatrics, vol. 127, no. 3, pp. e544-e551, 2011.

[77] J. S. Forsyth, S. A. Ogston, A. Clark, V. C. Du Florey, and P. W. Howie, "Relation between early introduction of solid food to infants and their weight and illnesses during the first two years of life," British Medical Journal, vol. 306, no. 6892, pp. 1572-1576, 1993.

[78] S. Brophy, R. Cooksey, M. B. Gravenor et al., "Risk factors for childhood obesity at age 5 : analysis of the millennium cohort study," BMC public health, vol. 9, p. 467, 2009.

[79] S. Sloan, A. Gildea, M. Stewart, H. Sneddon, and D. Iwaniec, "Early weaning is related to weight and rate of weight gain in infancy," Child: Care, Health and Development, vol. 34, no. 1, pp. 59-64, 2008.

[80] M. S. Kramer, R. G. Barr, D. G. Leduc, C. Boisjoly, L. McVeyWhite, and I. B. Pless, "Determinants of weight and adiposity in the first year of life," Journal of Pediatrics, vol. 106, pp. 10$14,1985$.

[81] K. K. Ong, P. M. Emmett, S. Noble, A. Ness, and D. B. Dunger, "Dietary energy intake at the age of 4 months predicts postnatal weight gain and childhood body mass index," Pediatrics, vol. 117, no. 3, pp. e503-e508, 2006.

[82] A. J. Stunkard, R. I. Berkowitz, V. A. Stallings, and D. A. Schoeller, "Energy intake, not energy output, is a determinant of body size in infants," American Journal of Clinical Nutrition, vol. 69, no. 3, pp. 524-530, 1999.

[83] M. Deheeger, M. Akrout, F. Bellisle, C. Rossignol, and M. F. Rolland-Cachera, "Individual patterns of food intake development in children: a 10 months to 8 years of age follow-up study of nutrition and growth," Physiology \& Behavior, vol. 59, pp. 403-407, 1996.

[84] L. Dubois, A. P. Farmer, M. Girard, and K. Peterson, "Preschool children's eating behaviours are related to dietary adequacy and body weight," European Journal of Clinical Nutrition, vol. 61, no. 7, pp. 846-855, 2007.

[85] A. J. Stunkard, R. I. Berkowitz, D. Schoeller, G. Maislin, and V. A. Stallings, "Predictors of body size in the first $2 \mathrm{y}$ of life: a high-risk study of human obesity," International Journal of Obesity and Related Metabolic Disorders, vol. 28, pp. 503-513, 2004.

[86] S. Lim, J. M. Zoellner, J. M. Lee et al., "Obesity and sugar-sweetened beverages in African-American preschool children: a longitudinal study," Obesity, vol. 17, pp. 12621268, 2009.

[87] T. L. LaRowe, A. K. Adams, J. B. Jobe, K. A. Cronin, S. M. Vannatter, and R. J. Prince, "Dietary intakes and physical activity among preschool-aged children living in rural American Indian communities before a family-based healthy lifestyle intervention," Journal of the American Dietetic Association, vol. 110, no. 7, pp. 1049-1057, 2010.

[88] M. Linardakis, K. Sarri, M. S. Pateraki, M. Sbokos, and A. Kafatos, "Sugar-added beverages consumption among kindergarten children of Crete: effects on nutritional status and risk of obesity," BMC Public Health, vol. 8, article no. 279, 2008.

[89] M. L. Warner, K. Harley, A. Bradman, G. Vargas, and B. Eskenazi, "Soda consumption and overweight status of 2year-old mexican-american children in california," Obesity, vol. 14, pp. 1966-1974, 2006.

[90] J. A. Welsh, M. E. Cogswell, S. Rogers, H. Rockett, Z. Mei, and L. M. Grummer-Strawn, "Overweight among low-income preschool children associated with the consumption of sweet drinks: Missouri, 1999-2002," Pediatrics, vol. 115, no. 2, pp. e223-e229, 2005.

[91] A. J. Ariza, E. H. Chen, H. J. Binns, and K. K. Christoffel, "Risk factors for overweight in five- to six-year-old HispanicAmerican children: a pilot study," Journal of Urban Health, vol. 81, no. 1, pp. 150-161, 2004.

[92] L. Dubois, A. Farmer, M. Girard, and K. Peterson, "Regular sugar-sweetened beverage consumption between meals increases risk of overweight among preschool-aged children," Journal of the American Dietetic Association, vol. 107, no. 6, pp. 924-934, 2007.

[93] L. M. Fiorito, M. Marini, L. A. Francis, H. Smiciklas-Wright, and L. L. Birch, "Beverage intake of girls at age 5 y predicts adiposity and weight status in childhood and adolescence," American Journal of Clinical Nutrition, vol. 90, no. 4, pp. 935942, 2009.

[94] J. A. Nelson, K. Carpenter, and M. A. Chiasson, "Diet, activity, and overweight among preschool-age children enrolled in the Special Supplemental Nutrition Program for Women, Infants, and Children (WIC)," Preventing Chronic Disease, vol. 3, no. 2, p. A49, 2006.

[95] H. M. Hendy, K. E. Williams, T. S. Camise, N. Eckman, and A. Hedemann, "The Parent Mealtime Action Scale (PMAS). Development and association with children's diet and weight," Appetite, vol. 52, no. 2, pp. 328-339, 2009.

[96] K. E. Leahy, L. L. Birch, and B. J. Rolls, "Reducing the energy density of multiple meals decreases the energy intake of preschool-age children," American Journal of Clinical Nutrition, vol. 88, no. 6, pp. 1459-1468, 2008. 
[97] K. E. Leahy, L. L. Birch, J. O. Fisher, and B. J. Rolls, "Reductions in entree energy density increase children's vegetable intake and reduce energy intake," Obesity, vol. 16, pp. 1559-1565, 2008.

[98] K. S. Wosje, P. R. Khoury, R. P. Claytor et al., "Dietary patterns associated with fat and bone mass in young children," American Journal of Clinical Nutrition, vol. 92, no. 2, pp. 294-303, 2010.

[99] K. Acharya, M. Feese, F. Franklin, and E. K. Kabagambe, "Body mass index and dietary intake among Head Start children and caregivers," Journal of the American Dietetic Association, vol. 111, pp. 1314-1321, 2011.

[100] K. F. Kavanagh, R. J. Cohen, M. J. Heinig, and K. G. Dewey, "Educational intervention to modify bottle-feeding behaviors among formula-feeding mothers in the WIC program: impact on infant formula intake and weight gain," Journal of Nutrition Education and Behavior, vol. 40, no. 4, pp. 244-250, 2008.

[101] J. Worobey, M. Islas Lopez, and D. J. Hoffman, "Maternal behavior and infant weight gain in the first year," Journal of Nutrition Education and Behavior, vol. 41, no. 3, pp. 169-175, 2009.

[102] A. L. Thompson, M. A. Mendez, J. B. Borja, L. S. Adair, C. R. Zimmer, and M. E. Bentley, "Development and validation of the Infant Feeding Style Questionnaire," Appetite, vol. 53, no. 2, pp. 210-221, 2009.

[103] A. E. Baughcum, K. A. Burklow, C. M. Deeks, S. W. Powers, and R. C. Whitaker, "Maternal feeding practices and childhood obesity: a focus group study of low-income mothers," Archives of Pediatrics and Adolescent Medicine, vol. 152, no. 10, pp. 1010-1014, 1998.

[104] C. Farrow and J. Blissett, "Does maternal control during feeding moderate early infant weight gain?" Pediatrics, vol. 118, no. 2, pp. e293-e298, 2006.

[105] M. Wake, J. M. Nicholson, P. Hardy, and K. Smith, "Preschooler obesity and parenting styles of mothers and fathers: Australian National Population study," Pediatrics, vol. 120, no. 6, pp. e1520-e1527, 2007.

[106] J. O. Fisher and L. L. Birch, "Restricting access to palatable foods affects children's behavioral response, food selection, and intake," American Journal of Clinical Nutrition, vol. 69, no. 6, pp. 1264-1272, 1999.

[107] J. O. Fisher and L. L. Birch, "Restricting access to foods and children's eating," Appetite, vol. 32, no. 3, pp. 405-419, 1999.

[108] M. S. Faith and J. Kerns, "Infant and child feeding practices and childhood overweight: the role of restriction," Maternal and Child Nutrition, vol. 1, no. 3, pp. 164-168, 2005.

[109] S. W. Powers, L. A. Chamberlin, K. B. van Schaick, S. N. Sherman, and R. C. Whitaker, "Maternal feeding strategies, child eating behaviors, and child BMI in low-income AfricanAmerican preschoolers," Obesity, vol. 14, pp. 2026-2033, 2006.

[110] K. Kröller and P. Warschburger, "Associations between maternal feeding style and food intake of children with a higher risk for overweight," Appetite, vol. 51, no. 1, pp. 166$172,2008$.

[111] J. L. Santos, J. Kain, P. Dominguez-Vásquez et al., "Maternal anthropometry and feeding behavior toward preschool children: association with childhood body mass index in an observational study of Chilean families," International Journal of Behavioral Nutrition and Physical Activity, vol. 6, article no. 93, 2009.
[112] J. E. Gregory, S. J. Paxton, and A. M. Brozovic, "Maternal feeding practices, child eating behaviour and body mass index in preschool-aged children: a prospective analysis," International Journal of Behavioral Nutrition and Physical Activity, vol. 7, article no. 55, 2010.

[113] J. S. Gubbels, S. P. J. Kremers, A. Stafleu et al., "Diet-related restrictive parenting practices. Impact on dietary intake of 2year-old children and interactions with child characteristics," Appetite, vol. 52, no. 2, pp. 423-429, 2009.

[114] J. A. Mendoza, F. J. Zimmerman, and D. A. Christakis, "Television viewing, computer use, obesity, and adiposity in US preschool children," International Journal of Behavioral Nutrition and Physical Activity, vol. 4, article no. 44, 2007.

[115] B. A. Dennison, T. A. Erb, and P. L. Jenkins, "Television viewing and television in bedroom associated with overweight risk among low-income preschool children," Pediatrics, vol. 109, no. 6, pp. 1028-1035, 2002.

[116] S. E. Anderson and R. C. Whitaker, "Household routines and obesity in US preschool-aged children," Pediatrics, vol. 125, no. 3, pp. 420-428, 2010.

[117] K. F. Janz, S. M. Levy, T. L. Burns, J. C. Torner, M. C. Willing, and J. J. Warren, "Fatness, physical activity, and television viewing in children during the adiposity rebound period: the Iowa bone development study," Preventive Medicine, vol. 35, no. 6, pp. 563-571, 2002.

[118] R. T. Kimbro, J. Brooks-Gunn, and S. McLanahan, "Young children in urban areas: links among neighborhood characteristics, weight status, outdoor play, and television watching," Social Science and Medicine, vol. 72, no. 5, pp. 668-676, 2011.

[119] E. Locard, N. Mamelle, A. Billette, M. Miginiac, F. Munoz, and S. Rey, "Risk factors of obesity in a five year old population. Parental versus environmental factors," International Journal of Obesity and Related Metabolic Disorders, vol. 16, pp. 721-729, 1992.

[120] J. C. Lumeng, S. Rahnama, D. Appugliese, N. Kaciroti, and R. H. Bradley, "Television exposure and overweight risk in preschoolers," Archives of Pediatrics and Adolescent Medicine, vol. 160, no. 4, pp. 417-422, 2006.

[121] N. F. Butte, "Impact of infant feeding practices on childhood obesity," Journal of Nutrition, vol. 139, no. 2, pp. 412S-416S, 2009.

[122] L. Monasta, G. D. Batty, A. Cattaneo et al., "Early-life determinants of overweight and obesity: a review of systematic reviews," Obesity Reviews, vol. 11, no. 10, pp. 695-708, 2010.

[123] E. M. Taveras, S. L. Rifas-Shiman, E. Oken, E. P. Gunderson, and M. W. Gillman, "Short sleep duration in infancy and risk of childhood overweight," Archives of Pediatrics and Adolescent Medicine, vol. 162, no. 4, pp. 305-311, 2008.

[124] L. Tikotzky, G. De Marcas, J. Har-Toov, S. Dollberg, Y. BarHaim, and A. Sadeh, "Sleep and physical growth in infants during the first 6 months," Journal of Sleep Research, vol. 19, no. 1, pp. 103-110, 2010.

[125] R. von Kries, A. M. Toschke, H. Wurmser, T. Sauerwald, and B. Koletzko, "Reduced risk for overweight and obesity in 5and 6-y-old children by duration of sleep-a cross-sectional study," International Journal of Obesity and Related Metabolic Disorders, vol. 26, pp. 710-716, 2002.

[126] M. Sekine, T. Yamagami, S. Hamanishi et al., "Parental obesity, lifestyle factors and obesity in preschool children: results of the Toyama Birth Cohort Study," Journal of Epidemiology, vol. 12, no. 1, pp. 33-39, 2002. 
[127] Z. Tian, T. Ye, X. Zhang et al., "Sleep duration and hyperglycemia among obese and nonobese children aged 3 to 6 years," Archives of Pediatrics and Adolescent Medicine, vol. 164, no. 1, pp. 46-52, 2010.

[128] A. J. Hammons and B. H. Fiese, "Is frequency of shared family meals related to the nutritional health of children and adolescents?" Pediatrics, vol. 127, no. 6, pp. e1565-e1574, 2011.

[129] K. Ong and R. Loos, "Rapid infancy weight gain and subsequent obesity: systematic reviews and hopeful suggestions," Acta Paediatrica, vol. 95, no. 8, pp. 904-908, 2006.

[130] J. Baird, D. Fisher, P. Lucas, J. Kleijnen, H. Roberts, and C. Law, "Being big or growing fast: systematic review of size and growth in infancy and later obesity," British Medical Journal, vol. 331, no. 7522, pp. 929-931, 2005.

[131] J. J. Reilly, J. Armstrong, A. R. Dorosty et al., "Early life risk factors for obesity in childhood: cohort study," British Medical Journal, vol. 330, no. 7504, pp. 1357-1359, 2005.

[132] N. Stettler, B. S. Zemel, S. Kumanyika, and V. A. Stallings, "Infant weight gain and childhood overweight status in a multicenter, cohort study," Pediatrics, vol. 109, no. 2, pp. 194199, 2002.

[133] L. L. Hui, C. M. Schooling, S. S. L. Leung et al., "Birth weight, infant growth, and childhood body mass index: Hong Kong's children of 1997 birth cohort," Archives of Pediatrics and Adolescent Medicine, vol. 162, no. 3, pp. 212-218, 2008.

[134] K. K. Ong, P. M. Emmett, S. Noble, A. Ness, and D. B. Dunger, "Dietary energy intake at the age of 4 months predicts postnatal weight gain and childhood body mass index," Pediatrics, vol. 117, no. 3, pp. e503-e508, 2006.

[135] N. Karaolis-Danckert, A. E. Buyken, M. Kulig et al., "How pre- and postnatal risk factors modify the effect of rapid weight gain in infancy and early childhood on subsequent fat mass development: results from the Multicenter Allergy Study 90," American Journal of Clinical Nutrition, vol. 87, no. 5, pp. 1356-1364, 2008.

[136] S. Chomtho, J. C. K. Wells, J. E. Williams, A. Lucas, and M. S. Fewtrell, "Associations between birth weight and later body composition: evidence from the 4-component model," American Journal of Clinical Nutrition, vol. 88, no. 4, pp. 1040-1048, 2008.

[137] J. Raisler, C. Alexander, and P. O'Campo, "Breast-feeding and infant illness: a dose-response relationship?" American Journal of Public Health, vol. 89, no. 1, pp. 25-30, 1999.

[138] R. A. Lawrence, "Increasing breastfeeding duration: changing the paradigm," Breastfeeding Medicine, vol. 6, pp. 367-368, 2011.

[139] R. E. Black, L. H. Allen, Z. A. Bhutta et al., "Maternal and child undernutrition: global and regional exposures and health consequences," The Lancet, vol. 371, no. 9608, pp. 243260, 2008.

[140] L. M. Grummer-Strawn, K. S. Scanlon, and S. B. Fein, "Infant feeding and feeding transitions during the first year of life," Pediatrics, vol. 122, no. 2, pp. S36-S42, 2008.

[141] C. G. Owen, R. M. Martin, P. H. Whincup, G. D. Smith, and D. G. Cook, "Effect of infant feeding on the risk of obesity across the life course: a quantitative review of published evidence," Pediatrics, vol. 115, no. 5, pp. 1367-1377, 2005.

[142] C. G. Owen, R. M. Martin, P. H. Whincup, G. Davey-Smith, M. W. Gillman, and D. G. Cook, "The effect of breastfeeding on mean body mass index throughout life: a quantitative review of published and unpublished observational evidence," American Journal of Clinical Nutrition, vol. 82, no. 6, pp. 1298-1307, 2005.

[143] M. A. Quigley, "Re: Duration of breastfeeding and risk of overweight: A meta-analysis," American Journal of Epidemiology, vol. 163, no. 9, pp. 870-872, 2006.

[144] T. Harder, R. Bergmann, G. Kallischnigg, and A. Plagemann, "Duration of breastfeeding and risk of overweight: a metaanalysis," American Journal of Epidemiology, vol. 162, no. 5, pp. 397-403, 2005.

[145] S. Arenz, R. Ruckerl, B. Koletzko, and R. von Kries, "Breastfeeding and childhood obesity-a systematic review," International Journal of Obesity and Related Metabolic Disorders, vol. 28, pp. 1247-1256, 2004.

[146] A. Beyerlein, A. M. Toschke, and R. Von Kries, "Breastfeeding and childhood obesity: shift of the entire BMI distribution or only the upper parts?" Obesity, vol. 16, no. 12, pp. 2730-2733, 2008.

[147] B. Koletzko, R. Von Kries, R. C. Monasterolo et al., "Can infant feeding choices modulate later obesity risk?" American Journal of Clinical Nutrition, vol. 89, no. 5, pp. 1502S-1508S, 2009.

[148] B. Koletzko, R. Von Kries, R. Closa et al., "Lower protein in infant formula is associated with lower weight up to age 2 y: a randomized clinical trial," American Journal of Clinical Nutrition, vol. 89, no. 6, pp. 1836-1845, 2009.

[149] M. J. Heinig, L. A. Nommsen, J. M. Peerson, B. Lonnerdal, and K. G. Dewey, "Energy and protein intakes of breastfed and formula-fed infants during the first year of life and their association with growth velocity: the DARLING Study," The American Journal of Clinical Nutrition, vol. 58, no. 2, pp. 152156, 1993.

[150] K. G. Dewey and B. Lonnerdal, "Infant self-regulation of breast milk intake," Acta Paediatrica Scandinavica, vol. 75, no. 6, pp. 893-898, 1986.

[151] K. Hendricks, R. Briefel, T. Novak, and P. Ziegler, "Maternal and child characteristics associated with infant and toddler feeding practices," Journal of the American Dietetic Association, vol. 106, no. 1, pp. S135-S148, 2006.

[152] American Academy of Pediatrics, Bright Futures Nutrition, The American Academy of Pediatrics, Elk Grove Village, Ill, USA, 2011.

[153] American Academy of Pediatrics, American Public Health Association and National Resource Center for Health and Safety in Child Care and Early Education, "Preventing Childhood Obesity in Early Care and Education: Selected Standards from Caring for Our Children: National Health and Safety Performance Standards; Guidelines for Early Care and Education Programs," 3rd Edition, August, 2010, http://nrckids.org/CFOC3/PDFVersion/preventing_obesity .pdf.

[154] U.S. Department of Agriculture, Food and Nutrition Service, "Feeding infants: A guide for use in the child nutrition programs," USDA, FNS, Alexandria, Va, USA, 2010, http://www.fns.usda.gov/tn/resources/feeding_infants.pdf.

[155] R. E. Kleinman, Ed., Pediatric Nutrition Handbook, American Academy of Pediatrics, Elk Grove Village, Ill, USA, 6th edition, 2009.

[156] A. M. Siega-Riz, D. M. Deming, K. C. Reidy, M. K. Fox, E. Condon, and R. R. Briefel, "Food consumption patterns of infants and toddlers: where are we now?" Journal of the American Dietetic Association, vol. 110, no. 12, pp. S38S51, 2010. 
[157] H. Wasser, M. Bentley, J. Borja et al., "Infants perceived as "fussy" are more likely to receive complementary foods before 4 months," Pediatrics, vol. 127, no. 2, pp. 229-237, 2011.

[158] L. M. Atkin and P. S. W. Davies, "Diet composition and body composition in preschool children," American Journal of Clinical Nutrition, vol. 72, no. 1, pp. 15-21, 2000.

[159] T. M. O'Connor, S. J. Yang, and T. A. Nicklas, "Beverage intake among preschool children and its effect on weight status," Pediatrics, vol. 118, no. 4, pp. e1010-e1018, 2006.

[160] P. O. A. Monteiro and C. G. Victora, "Rapid growth in infancy and childhood and obesity in later life-a systematic review," Obesity Reviews, vol. 6, no. 2, pp. 143-154, 2005.

[161] I. E. Axelsson, I. Jakobsson, and N. C. R. Raiha, "Formula with reduced protein content: effects on growth and protein metabolism during weaning," Pediatric Research, vol. 24, no. 3, pp. 297-301, 1988.

[162] A. L. B. Günther, A. E. Buyken, and A. Kroke, "Protein intake during the period of complementary feeding and early childhood and the association with body mass index and percentage body fat at $7 \mathrm{y}$ of age," American Journal of Clinical Nutrition, vol. 85, no. 6, pp. 1626-1633, 2007.

[163] I. Gunnarsdottir and I. Thorsdottir, "Relationship between growth and feeding in infancy and body mass index at the age of 6 years," International Journal of Obesity and Related Metabolic Disorders, vol. 27, pp. 1523-1527, 2003.

[164] R. R. Briefel, L. M. Kalb, E. Condon et al., "The Feeding Infants and Toddlers Study 2008: study design and methods," Journal of the American Dietetic Association, vol. 110, no. 12, pp. S16-S26, 2010.

[165] B. Devaney, L. Kalb, R. Briefel, T. Zavitsky-Novak, N. Clusen, and P. Ziegler, "Feeding Infants and Toddlers Study: overview of the study design," Journal of the American Dietetic Association, vol. 104, no. 1, pp. S8-S13, 2004.

[166] M. K. Fox, E. Condon, R. R. Briefel, K. C. Reidy, and D. M. Deming, "Food consumption patterns of young preschoolers: are they starting off on the right path?" Journal of the American Dietetic Association, vol. 110, no. 12, pp. S52S59, 2010.

[167] R. A. Forshee, M. L. Storey, and P. A. Anderson, "Reply to VS Malik et al," American Journal of Clinical Nutrition, vol. 89, no. 1, pp. 439-440, 2009.

[168] V. S. Malik, W. C. Willett, and F. B. Hu, "Sugar-sweetened beverages and BMI in children and adolescents: reanalyses of a meta-analysis," American Journal of Clinical Nutrition, vol. 89, no. 1, pp. 438-439, 2009.

[169] R. R. Briefel, K. Reidy, V. Karwe, and B. Devaney, "Feeding Infants and Toddlers Study: improvements needed in meeting infant feeding recommendations," Journal of the American Dietetic Association, vol. 104, no. 1, pp. S31-S37, 2004.

[170] J. T. Dwyer, N. F. Butte, D. M. Deming, A. M. Siega-Riz, and K. C. Reidy, "Feeding Infants and Toddlers Study 2008: progress, continuing concerns, and implications," Journal of the American Dietetic Association, vol. 110, no. 12, pp. S60S67, 2010.

[171] J. D. Skinner, P. Ziegler, S. Pac, and B. Devaney, "Meal and snack patterns of infants and toddlers," Journal of the American Dietetic Association, vol. 104, no. 1, pp. S65-S70, 2004.

[172] M. K. Fox, B. Devaney, K. Reidy, C. Razafindrakoto, and P. Ziegler, "Relationship between portion size and energy intake among infants and toddlers: evidence of self-regulation,"
Journal of the American Dietetic Association, vol. 106, no. 1, pp. S77-S83, 2006.

[173] S. J. Fomon, L. J. Filmer Jr., L. N. Thomas, T. A. Anderson, and S. E. Nelson, "Influence of formula concentration on caloric intake and growth of normal infants," Acta paediatrica Scandinavica, vol. 64, pp. 172-181, 1975.

[174] L. L. Birch and M. Deysher, "Caloric compensation and sensory specific satiety: evidence for self regulation of food intake by young children," Appetite, vol. 7, no. 4, pp. 323-331, 1986.

[175] B. J. Rolls, D. Engell, and L. L. Birch, "Serving portion size influences 5-year-old but not 3-year-old children's food intakes," Journal of the American Dietetic Association, vol. 100, no. 2, pp. 232-234, 2000.

[176] K. E. Rhee, J. C. Lumeng, D. P. Appugliese, N. Kaciroti, and R. H. Bradley, "Parenting styles and overweight status in first grade," Pediatrics, vol. 117, no. 6, pp. 2047-2054, 2006.

[177] S. O. Hughes, R. M. Shewchuk, M. L. Baskin, T. A. Nicklas, and H. Qu, "Indulgent feeding style and children's weight status in preschool," Journal of Developmental and Behavioral Pediatrics, vol. 29, no. 5, pp. 403-410, 2008.

[178] J. L. Chen and C. Kennedy, "Factors associated with obesity in Chinese-American children," Pediatric nursing, vol. 31, no. 2, pp. 110-115, 2005.

[179] P. A. Graziano, S. D. Calkins, and S. P. Keane, "Toddler selfregulation skills predict risk for pediatric obesity," International Journal of Obesity, vol. 34, no. 4, pp. 633-641, 2010.

[180] S. Carnell and J. Wardle, "Appetite and adiposity in children: evidence for a behavioral susceptibility theory of obesity," American Journal of Clinical Nutrition, vol. 88, no. 1, pp. 2229, 2008.

[181] D. Spruijt-Metz, C. H. Lindquist, L. L. Birch, J. O. Fisher, and M. I. Goran, "Relation between mothers' child-feeding practices and children's adiposity," American Journal of Clinical Nutrition, vol. 75, no. 3, pp. 581-586, 2002.

[182] K. Kroller and P. Warschburger, "Maternal feeding strategies and child's food intake: considering weight and demographic influences using structural equation modeling," International Journal of Behavioral Nutrition and Physical Activity, vol. 6: 78, 2009.

[183] E. Satter, "Feeding is parenting," The Vision Times, no. 4, pp. 1-4, 2006.

[184] H. Patrick and T. A. Nicklas, "A review of family and social determinants of children's eating patterns and diet quality," Journal of the American College of Nutrition, vol. 24, no. 2, pp. 83-92, 2005.

[185] S. L. Hoerr, S. O. Hughes, J. O. Fisher, T. A. Nicklas, Y. Liu, and R. M. Shewchuk, "Associations among parental feeding styles and children's food intake in families with limited incomes," International Journal of Behavioral Nutrition and Physical Activity, vol. 6, article 55, 2009.

[186] H. Patrick, T. A. Nicklas, S. O. Hughes, and M. Morales, “The benefits of authoritative feeding style: caregiver feeding styles and children's food consumption patterns," Appetite, vol. 44, no. 2, pp. 243-249, 2005.

[187] J. M. Berge, M. Wall, D. Neumark-Sztainer, N. Larson, and M. Story, "Parenting style and family meals: cross-sectional and 5-year longitudinal associations," Journal of the American Dietetic Association, vol. 110, no. 7, pp. 1036-1042, 2010.

[188] T. A. Nicklas, T. Baranowski, J. C. Baranowski, K. Cullen, L. Rittenberry, and N. Olvera, "Family and child-care provider influences on preschool children's fruit, juice, and vegetable 
consumption," Nutrition Reviews, vol. 59, no. 7, pp. 224-235, 2001.

[189] J. L. Carper, J. Orlet Fisher, and L. L. Birch, "Young girls' emerging dietary restraint and disinhibition are related to parental control in child feeding," Appetite, vol. 35, no. 2, pp. 121-129, 2000.

[190] J. O. Fisher and L. L. Birch, "Parents' restrictive feeding practices are associated with young girls' negative self-evaluation of eating," Journal of the American Dietetic Association, vol. 100, no. 11, pp. 1341-1346, 2000.

[191] L. L. Birch, J. O. Fisher, and K. K. Davison, "Learning to overeat: maternal use of restrictive feeding practices promotes girls' eating in the absence of hunger," American Journal of Clinical Nutrition, vol. 78, no. 2, pp. 215-220, 2003.

[192] M. S. Faith, K. S. Scanlon, L. L. Birch, L. A. Francis, and B. Sherry, "Parent-child feeding strategies and their relationships to child eating and weight status," Obesity Research, vol. 12, no. 11, pp. 1711-1722, 2004.

[193] L. A. Francis and L. L. Birch, "Maternal weight status modulates the effects of restriction on daughters' eating and weight," International Journal of Obesity, vol. 29, no. 8, pp. 942-949, 2005.

[194] H. L. Burdette, R. C. Whitaker, W. C. Hall, and S. R. Daniels, "Maternal infant-feeding style and children's adiposity at 5 years of age," Archives of Pediatrics and Adolescent Medicine, vol. 160, no. 5, pp. 513-520, 2006.

[195] A. K. Ventura and L. L. Birch, "Does parenting affect children's eating and weight status?" International Journal of Behavioral Nutrition and Physical Activity, vol. 5, article no. $15,2008$.

[196] S. L. Anzman, B. Y. Rollins, and L. L. Birch, "Parental influence on children's early eating environments and obesity risk: implications for prevention," International Journal of Obesity, vol. 34, no. 7, pp. 1116-1124, 2010.

[197] L. Hubbs-Tait, T. S. Kennedy, M. C. Page, G. L. Topham, and A. W. Harrist, "Parental Feeding Practices Predict Authoritative, Authoritarian, and Permissive Parenting Styles," Journal of the American Dietetic Association, vol. 108, no. 7, pp. 11541161, 2008.

[198] S. E. Barlow, "Expert committee recommendations regarding the prevention, assessment, and treatment of child and adolescent overweight and obesity: summary report," Pediatrics, vol. 120, pp. S164-S192, 2007.

[199] F. J. Zimmerman, D. A. Christakis, and A. N. Meltzoff, "Television and DVD/video viewing in children younger than 2 years," Archives of Pediatrics and Adolescent Medicine, vol. 161, no. 5, pp. 473-479, 2007.

[200] L. K. Certain and R. S. Kahn, "Prevalence, correlates, and trajectory of television viewing among infants and toddlers," Pediatrics, vol. 109, no. 4, pp. 634-642, 2002.

[201] S. A. Miller, E. M. Taveras, S. L. Rifas-Shiman, and M. W. Gillman, "Association between television viewing and poor diet quality in young children," International Journal of Pediatric Obesity, vol. 3, no. 3, pp. 168-176, 2008.

[202] M. A. Horodynski, M. Stommel, H. E. Brophy-Herb, and L. Weatherspoon, "Mealtime television viewing and dietary quality in low-income African American and Caucasian mother-toddler dyads," Maternal and Child Health Journal, vol. 14, no. 4, pp. 548-556, 2010.

[203] D. M. Matheson, Y. Wang, L. M. Klesges, B. M. Beech, H. C. Kraemer, and T. N. Robinson, "African-American girls' dietary intake while watching television," Obesity research, vol. 12, pp. 32S-37S, 2004.
[204] D. M. Matheson, J. D. Killen, Y. Wang, A. Varady, and T. N. Robinson, "Children's food consumption during television viewing," American Journal of Clinical Nutrition, vol. 79, no. 6, pp. 1088-1094, 2004.

[205] S. Feldman, M. E. Eisenberg, D. Neumark-Sztainer, and M. Story, "Associations between watching TV during family meals and dietary intake among adolescents," Journal of Nutrition Education and Behavior, vol. 39, no. 5, pp. 257-263, 2007.

[206] American Academy of Pediatrics, "Back to sleep, tummy to play," 2008.

[207] A. S. Ammerman, D. S. Ward, S. E. Benjamin et al., "An intervention to promote healthy weight: Nutrition and Physical Activity Self-Assessment for Child Care (NAP SACC) theory and design," Preventing chronic disease, vol. 4, no. 3: A67, 2007.

[208] S. E. Benjamin, A. Ammerman, J. Sommers, J. Dodds, B. Neelon, and D. S. Ward, "Nutrition and physical activity selfassessment for child care (NAP SACC): results from a pilot intervention," Journal of Nutrition Education and Behavior, vol. 39, no. 3, pp. 142-149, 2007.

[209] National Association for Sport and Physical Education, Active start: A statement of physical activity guidelines for children birth to five years, NASPE, Washington, DC, USA, 2002.

[210] American Physical Therapy Association, "Lack of time on tummy shown to hinder achievement of developmental milestones, say physical therapists," 2008, http://www.apta.org/.

[211] E. Locard, N. Mamelle, A. Billette, M. Miginiac, F. Munoz, and S. Rey, "Risk factors of obesity in a five year old population. Parental versus environmental factors," International Journal of Obesity and Related Metabolic Disorders, vol. 16, pp. 721-729, 1992.

[212] E. Touchette, D. Petit, J. Paquet et al., "Factors associated with fragmented sleep at night across early childhood," Archives of Pediatrics and Adolescent Medicine, vol. 159, no. 3, pp. 242249, 2005.

[213] D. Wolke, R. Meyer, B. Ohrt, and K. Riegel, "The incidence of sleeping problems in preterm and fullterm infants discharged from neonatal special care units: an epidemiological longitudinal study," Journal of Child Psychology and Psychiatry and Allied Disciplines, vol. 36, no. 2, pp. 203-223, 1995.

[214] O. G. Jenni, L. Molinari, J. A. Caflisch, and R. H. Largo, "Sleep duration from ages 1 to 10 years: variability and stability in comparison with growth," Pediatrics, vol. 120, no. 4, pp. e769-e776, 2007.

[215] D. Al-Disi, N. Al-Daghri, L. Khanam et al., "Subjective sleep duration and quality influence diet composition and circulating adipocytokines and ghrelin levels in teen-age girls," Endocrine Journal, vol. 57, no. 10, pp. 915-923, 2010.

[216] E. vanCauter and K. L. Knutson, "Sleep and the epidemic of obesity in children and adults," European Journal of Endocrinology, vol. 159, supplement 1, pp. S59-S66, 2008.

[217] S. J. Motivala, A. J. Tomiyama, M. Ziegler, S. Khandrika, and M. R. Irwin, "Nocturnal levels of ghrelin and leptin and sleep in chronic insomnia," Psychoneuroendocrinology, vol. 34, no. 4, pp. 540-545, 2009.

[218] R. J. James, R. F. Drewett, and T. D. Cheetham, "Low cord ghrelin levels in term infants are associated with slow weight gain over the first 3 months of life," The Journal of Clinical Endocrinology \& Metabolism, vol. 89, pp. 3847-3850, 2004.

[219] E. A. Hodges, S. O. Hughes, J. Hopkinson, and J. O. Fisher, "Maternal decisions about the initiation and termination of infant feeding," Appetite, vol. 50, no. 2-3, pp. 333-339, 2008. 
[220] J. A. Scott, C. W. Binns, K. I. Graham, and W. H. Oddy, "Predictors of the early introduction of solid foods in infants: results of a cohort study," BMC Pediatrics, vol. 9, article 60, 2009.

[221] M. J. Heinig, J. R. Follett, K. D. Ishii, K. KavanaghProchaska, R. Cohen, and J. Panchula, "Barriers to compliance with infant-feeding recommendations among lowincome women," Journal of Human Lactation, vol. 22, no. 1, pp. 27-38, 2006.

[222] E. M. Taveras, K. Blackburn, M. W. Gillman et al., "First steps for mommy and me: a pilot intervention to improve nutrition and physical activity behaviors of postpartum mothers and their infants," Maternal and Child Health Journal, vol. 15, no. 8, pp. 1217-1227, 2011.

[223] I. M. Paul, J. S. Savage, S. L. Anzman et al., "Preventing obesity during infancy: a pilot study," Obesity, vol. 19, no. 2, pp. 353-361, 2011.

[224] I. M. Paul, C. J. Bartok, D. S. Downs, C. A. Stifter, A. K. Ventura, and L. L. Birch, "Opportunities for the primary prevention of obesity during infancy," Advances in Pediatrics, vol. 56, no. 1, pp. 107-133, 2009.

[225] American Academy of Pediatrics, "What families can do at home," 2011, http://www2.aap.org/obesity/families.html.

[226] P. J. Ciampa, D. Kumar, S. L. Barkin et al., "Interventions aimed at decreasing obesity in children younger than 2 years: a systematic review," Archives of Pediatrics and Adolescent Medicine, vol. 164, no. 12, pp. 1098-1104, 2010.

[227] K. Campbell, K. Hesketh, D. Crawford, J. Salmon, K. Ball, and Z. McCallum, "The Infant Feeding Activity and Nutrition Trial (INFANT) an early intervention to prevent childhood obesity: cluster-randomised controlled trial," BMC Public Health, vol. 8, article no. 103, 2008.

[228] L. A. Daniels, A. Magarey, D. Battistutta et al., "The NOURISH randomised control trial: positive feeding practices and food preferences in early childhood-a primary prevention program for childhood obesity," BMC Public Health, vol. 9, article no. 387, 2009.

[229] R. G. Watt, K. I. Tull, R. Hardy et al., "Effectiveness of a social support intervention on infant feeding practices: randomised controlled trial," Journal of Epidemiology and Community Health, vol. 63, no. 2, pp. 156-162, 2009.

[230] P. Brambilla, G. Bedogni, C. Buongiovanni et al., "'Mi voglio bene': a pediatrician-based randomized controlled trial for the prevention of obesity in Italian preschool children," Italian journal of pediatrics, vol. 36, p. 55, 2010.

[231] J. A. Groner, T. Skybo, L. Murray-Johnson et al., "Anticipatory guidance for prevention of childhood obesity: design of the MOMS project," Clinical Pediatrics, vol. 48, no. 5, pp. 483-492, 2009.

[232] L. M. Wen, M. De Domenico, D. Elliott, J. Bindon, and C. Rissel, "Evaluation of a feasibility study addressing risk factors for childhood obesity through home visits," Journal of Paediatrics and Child Health, vol. 45, no. 10, pp. 577-581, 2009.

[233] J. Barlow, S. Whitlock, S. Hanson et al., "Preventing obesity at weaning: parental views about the EMPOWER programme," Child: Care, Health and Development, vol. 36, no. 6, pp. 843$849,2010$. 


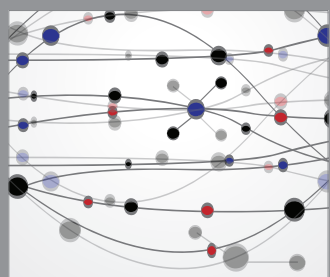

The Scientific World Journal
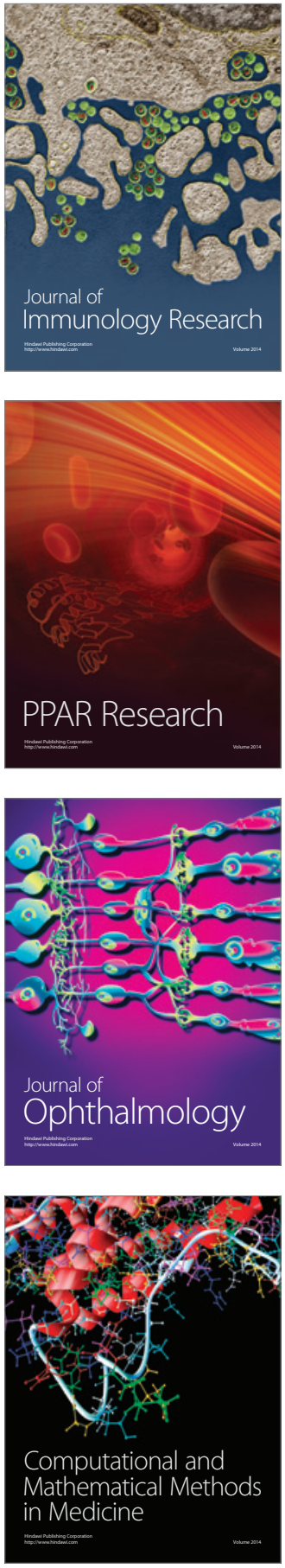

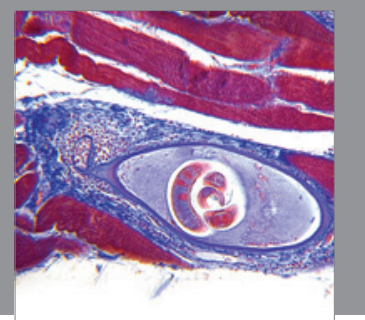

Gastroenterology

Research and Practice
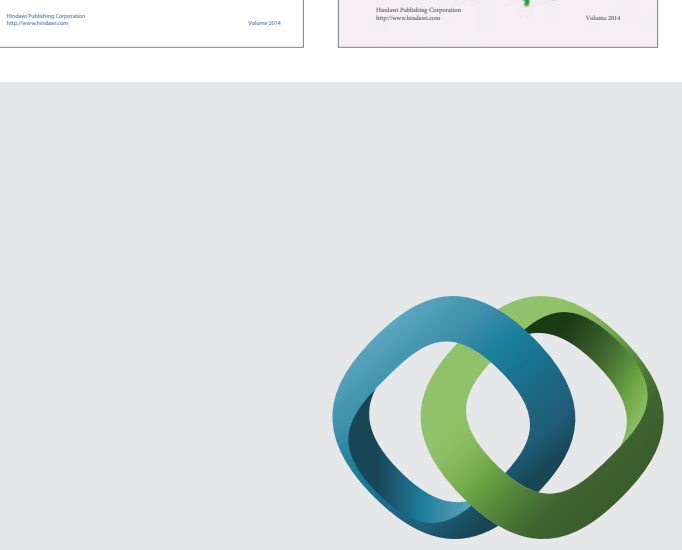

\section{Hindawi}

Submit your manuscripts at

http://www.hindawi.com
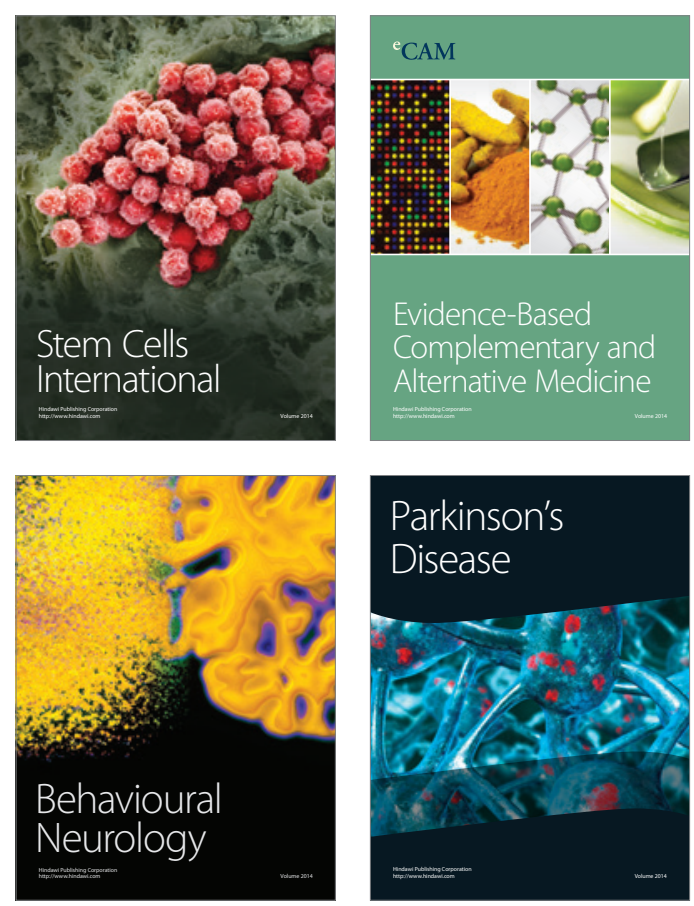

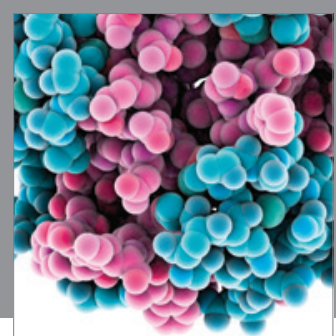

Journal of
Diabetes Research

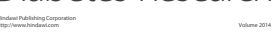

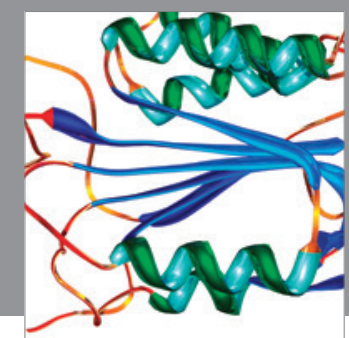

Disease Markers
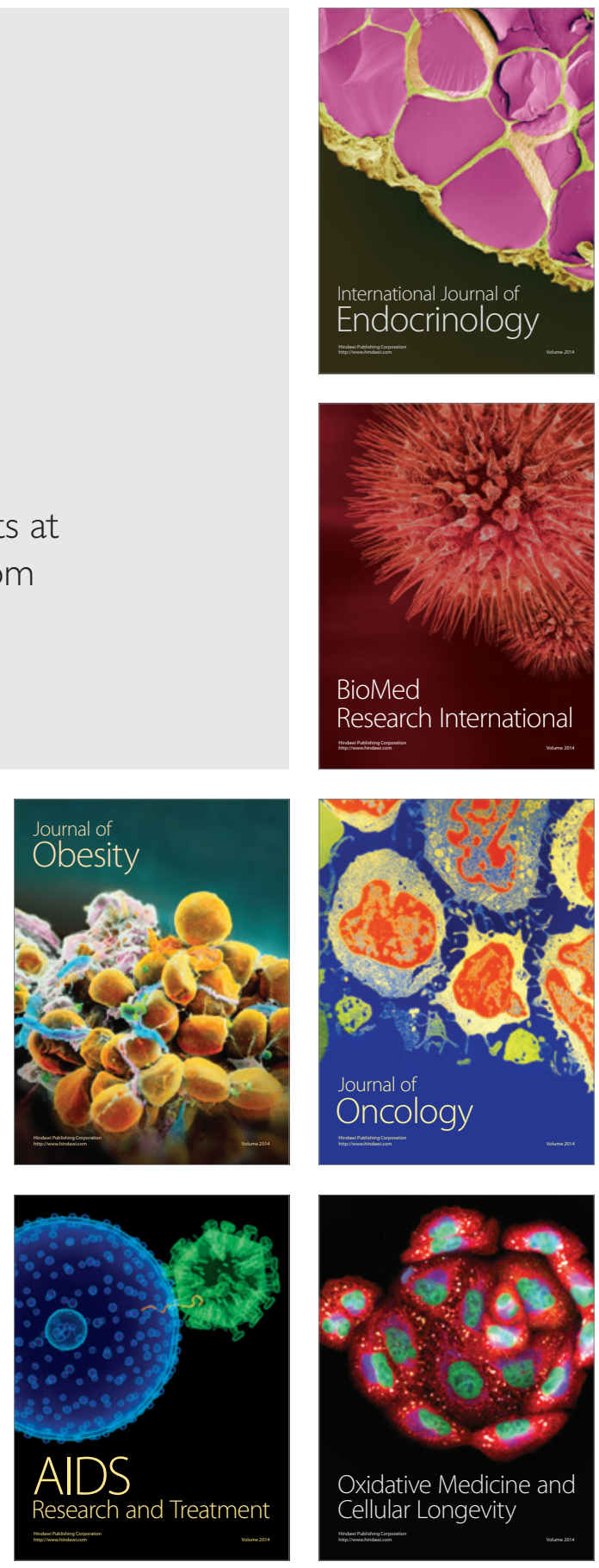